\title{
Therapy-induced stress response is associated with downregulation of pre- mRNA splicing in cancer cells
}

\author{
Ksenia S. Anufrieva ${ }^{1,2,3^{*}}$ D, Victoria O. Shender ${ }^{1,2^{*}}$, Georgij P. Arapidi ${ }^{1,2,3}$, Marat S. Pavlyukov ${ }^{4}$,
} Michail I. Shakhparonov ${ }^{4}$, Polina V. Shnaider ${ }^{1,2}$, Ivan O. Butenko ${ }^{5}$, Maria A. Lagarkova ${ }^{2}$ and Vadim M. Govorun ${ }^{1,5}$

\begin{abstract}
Background: Abnormal pre-mRNA splicing regulation is common in cancer, but the effects of chemotherapy on this process remain unclear.

Methods: To evaluate the effect of chemotherapy on slicing regulation, we performed meta-analyses of previously published transcriptomic, proteomic, phosphoproteomic, and secretome datasets. Our findings were verified by LC-MS/MS, western blotting, immunofluorescence, and FACS analyses of multiple cancer cell lines treated with cisplatin and pladienolide B.

Results: Our results revealed that different types of chemotherapy lead to similar changes in alternative splicing by inducing intron retention in multiple genes. To determine the mechanism underlying this effect, we analyzed gene expression in 101 cell lines affected by $\gamma$-irradiation, hypoxia, and 10 various chemotherapeutic drugs. Strikingly, only genes involved in the cell cycle and pre-mRNA splicing regulation were changed in a similar manner in all 335 tested samples regardless of stress stimuli. We revealed significant downregulation of gene expression levels in these two pathways, which could be explained by the observed decrease in splicing efficiency and global intron retention. We showed that the levels of active spliceosomal proteins might be further post-translationally decreased by phosphorylation and export into the extracellular space. To further explore these bioinformatics findings, we performed proteomic analysis of cisplatin-treated ovarian cancer cells. Finally, we demonstrated that the splicing inhibitor pladienolide B impairs the cellular response to DNA damage and significantly increases the sensitivity of cancer cells to chemotherapy.
\end{abstract}

Conclusions: Decreased splicing efficiency and global intron retention is a novel stress response mechanism that may promote survival of malignant cells following therapy. We found that this mechanism can be inhibited by pladienolide B, which significantly increases the sensitivity of cancer cells to cisplatin which makes it a good candidate drug for improving the efficiency of cancer therapy.

Keywords: Alternative splicing, Cell cycle, Chemotherapy, DNA damage response, Spliceosome, Pladienolide B

\footnotetext{
*Correspondence: anufrieva@phystech.edu; victoria.shender@gmail.com 'Laboratory of Proteomics, Shemyakin-Ovchinnikov Institute of Bioorganic Chemistry of the Russian Academy of Sciences, Moscow 117997, Russia Full list of author information is available at the end of the article
}

(c) The Author(s). 2018 Open Access This article is distributed under the terms of the Creative Commons Attribution 4.0 International License (http://creativecommons.org/licenses/by/4.0/), which permits unrestricted use, distribution, and reproduction in any medium, provided you give appropriate credit to the original author(s) and the source, provide a link to the Creative Commons license, and indicate if changes were made. The Creative Commons Public Domain Dedication waiver (http://creativecommons.org/publicdomain/zero/1.0/) applies to the data made available in this article, unless otherwise stated. 


\section{Background}

Chemo- and radiotherapy combined with surgical removal of a tumor remain the most common treatment for cancer. However, this treatment is complicated by the development of drug resistance in cancer cells which leads to tumor recurrence $[1,2]$. Therapy resistance can be attributed to a variety of mechanisms, such as DNA mutations, alterations in gene expression level, and abnormalities in pre-mRNA splicing [1-3]. The first two of these mechanisms are well studied, whereas the role of the pre-mRNA splicing regulation in development of chemotherapy resistance remains unclear [4].

Alternative pre-mRNA splicing is a process that affects more than $90 \%$ of multi-exon human genes. It allows cells to rapidly switch gene expression towards the production of various protein isoforms or noncoding transcripts and totally change the entire exome, proteome, and ultimately the cell phenotype [5-7]. Multiple pre-mRNA splicing abnormalities have been found in malignant cells leading to functional and nonfunctional changes in the proteome [8-11]. Further splicing perturbations were observed following chemotherapy. Several studies have described alternative splicing events that occur in cancer cells after treatment; however, most of these studies were focused on the function of specific genes rather than global changes in the transcriptome [12-17].

Most types of anticancer therapy frequently used in clinical practice are based on direct or indirect induction of DNA damage in target cells. The cellular response to DNA damage is a very complex process that includes stalling of RNA polymerase II, activation of multiple kinases (i.e., ATM, ATR, and DNA-PK), phosphorylation of histone H2AX, and cell cycle arrest [1, 18, 19]. These mechanisms allow tumor cells to repair DNA damage and survive following treatment. It has been recently reported that the splicing regulatory proteins may also play an important role in the DNA damage response and promote resistance to genotoxic stress by combining both splicing-dependent and splicing-independent mechanisms [20, 21].

Several small molecule splicing inhibitors were proposed lately to treat different types of cancer such as chronic lymphocytic leukemia, breast adenocarcinoma, prostate cancer, ovarian adenocarcinoma, and colon adenocarcinoma [22-24]. The most commonly used splicing inhibitors are pladienolide B and spliceostatin A. Both compounds bind to SF3B1 complex, blocking the spliceosome [25]. These small molecules were confirmed to effectively eliminate cancer cells both in vitro and in vivo; however, phase I clinical trials revealed multiple side effects due to high toxicity of the compounds [24].

In this study, we analyzed transcriptome data from patient-derived xenograft tumors and cancer cell lines to detect global changes in pre-mRNA splicing induced by multiple anticancer drugs. In addition, we comprehensively explored alterations in spliceosomal proteins. Particular, we used (I) mRNA microarray gene expression data from 101 cell lines derived from a variety of cancers, (II) quantitative phosphoproteome data, and (III) proteomic datasets of cells affected by various stress stimuli. We also tested the effect of the small molecule splicing inhibitor pladienolide B on the sensitivity of cancer cells to cisplatin.

\section{Methods}

\section{Alternative splicing analysis}

Unprocessed RNA-Seq reads were downloaded from the NCBI Gene Expression Omnibus (GEO) data repository (accession numbers GSE69405 and GSE89127; Table 1) [26]. To increase read quality before mapping, paired reads were trimmed using Trimmomatic (v. 0.35). The rMATS splicing tool [27] requires reads with a fixed length, so we trimmed reads from datasets GSE69405 and GSE89127 to the lengths of 96 and 90, respectively. We mapped trimmed RNA-Seq reads to hg19 of Gencode using STAR (v. 2.5.2b) according to recommendations from the STAR manual 2.4.0.1 with the following parameters: the maximum number of mismatches for paired reads was $4 \%$ of the read length, the maximum number of multiple alignments allowed for a read was 10 , non-canonical junctions were removed, the minimum number of allowed splice overhangs was 8 for unannotated junctions and 1 for annotated junctions, the minimum intron length was 20 , the maximum intron length was 1,000,000, and the number of "spurious" junctions was reduced. To compare splicing events before and after chemotherapy, we ran rMATS [27] splicing tool using the following parameters recommended by the developers: -c 0.0001 and -novel SS1 (multi-align reads are ignored as a default). Minor splicing differences were filtered out by thresholds of FDR $<0.05$ and IncLevelDifference value $>5 \%$. Splicing events were considered identical if they had the same coordinates and IncLevelDifference values had the same sign.

\section{Gene expression analysis}

In total, 26 microarray datasets (for dataset accession numbers see Table 1 and Additional file 1) were loaded from two repositories: NCBI GEO [26] and EMBL-EBI ArrayExpress [28]. Raw microarray data from Affymetrix microarrays (CEL files) were processed using the affy $R /$ Bioconductor package [29] with the following parameters: normalization-quantiles, background correctionrma, probe specific correction-pmonly, and summary method-medianpolish. The final data were already log-transformed. The lumi [30] and limma [31] R/Bioconductor packages were used to process the data obtained from Illumina Beadchips. The parameters were as 
Table 1 The mRNA microarray gene expression and RNA-Seq data used in this study. The dataset title is used hereafter as a dataset identifier

\begin{tabular}{|c|c|c|c|c|}
\hline \multirow[t]{2}{*}{ Dataset } & \multirow[t]{2}{*}{ Cancer type } & \multirow{2}{*}{$\begin{array}{l}\text { Time after } \\
\text { treatment (h) }\end{array}$} & \multicolumn{2}{|c|}{ Number of samples } \\
\hline & & & Control & After treatment \\
\hline \multicolumn{5}{|l|}{ I. Platinum-based agents } \\
\hline E-GEOD-38122 [103] & Hepatocyte carcinoma & 24 & 3 & 3 \\
\hline GSE47980 [104] & Melanoma & 24 & 9 & 9 \\
\hline GSE38545 & Ovarian cancer & 24 & 3 & 3 \\
\hline GSE13525 [105] & Ovarian cancer & 24 & 2 & 2 \\
\hline E-GEOD-8057 [106] & Ovarian cancer & 24 & 4 & 4 \\
\hline GSE51952 [107] & Hepatocyte carcinoma & 24 & 3 & 3 \\
\hline GSE66493 & Glioblastoma & 24 & 3 & 3 \\
\hline GDS3910 [108] & Breast cancer & 11 & 2 & 2 \\
\hline E-MTAB-3645 [109] & Ovarian cancer & 72 & 3 & 3 \\
\hline \multicolumn{5}{|l|}{ II. Paclitaxel } \\
\hline E-GEOD-50831 [110] & Ovarian cancer & 24 & 63 & 63 \\
\hline E-GEOD-50830 [110] & Endometrial adenocarcinoma & 24 & 55 & 57 \\
\hline E-GEOD-50811 [110] & Breast cancer & 24 & 79 & 81 \\
\hline \multicolumn{5}{|c|}{ III. Irradiation (two meta-analyses for cancer and embryonic cells) } \\
\hline E-GEOD-59732 [111] & Breast cancer & 24 & 48 & 48 \\
\hline E-GEOD-59861 [112] & Skin fibroblasts & $0,3,6,12,24$ & 4 & 12 \\
\hline \multicolumn{5}{|l|}{ IV. Hypoxia } \\
\hline E-GEOD-18494 [113] & Hepatocyte carcinoma, glioblastoma, breast cancer & 12 & 9 & 9 \\
\hline E-GEOD-53012 [114] & Prostate cancer, ovarian cancer, melanoma & 72 & 9 & 9 \\
\hline E-MTAB-3645 [109] & Ovarian cancer & 72 & 3 & 3 \\
\hline E-GEOD-17188 [115] & Breast cancer & 24 & 4 & 4 \\
\hline \multicolumn{5}{|c|}{ V. Tyrosine kinase inhibitors } \\
\hline E-TABM-585 [116] & Lung cancer & 20 & 21 & 27 \\
\hline \multicolumn{5}{|c|}{ VI. Topoisomerase inhibitors } \\
\hline E-GEOD-47013 [117] & Multiple myeloma & - & 3 & 3 \\
\hline E-GEOD-13477 [1 18] & Breast cancer & 24 & 2 & 2 \\
\hline E-GEOD-19638 [119] & Breast cancer & - & 2 & 2 \\
\hline E-GEOD-39870 [120] & Breast cancer & - & 3 & 3 \\
\hline \multicolumn{5}{|l|}{ Splicing analysis } \\
\hline GSE69405 [37] & Lung adenocarcinoma & 48 & 12 & 12 \\
\hline GSE89127 [34] & Gastric carcinoma, lung adenocarcinoma, melanoma, urinary bladder carcinoma & 48 & 18 & 18 \\
\hline \multicolumn{5}{|l|}{ Spliceostatin } \\
\hline GSE72156 [58] & Cervical cancer & - & 3 & 3 \\
\hline \multicolumn{5}{|l|}{ Pladienolide } \\
\hline E-GEOD-67770 [57] & Ovarian cancer & - & 2 & 2 \\
\hline
\end{tabular}

follows: variance stabilization- $\log 2$ and normalizationquantiles. Before that, an initial detection $p$ value threshold of 0.05 was chosen based on Illumina recommendations. rMeanSignal and gMeanSignal were taken as the values of the Agilent microarray signal. For further analysis of the data obtained from Agilent microarrays, the logarithm of the rMeanSignal-to-gMeanSignal ratio was normalized using the quantile normalization method.

Gene expression was compared between two group of cells (intact cells and exposed to stress: chemotherapy, radiotherapy, or hypoxia) using the limma R/Bioconductor package [31]. 


\section{Gene expression results aggregation}

The advantage of our analysis was that we combined $p$ values of separate datasets with the use of Wilkinson's method [32] for meta-analysis of significance values from metap R/Bioconductor package [33]. First, we considered $p$ values of differentially expressed genes using the limma R/Bioconductor package [31], and then, we combined $p$ values with the method of Wilkinson and made a correction for multiple testing with the FDR method. Methods for combining $p$ values gives a statistician flexibility, since they require minimal information and assumptions from gene expression studies, and thus, we did not account for the variability in the datasets or microarray platforms.

Meta-analysis of cisplatin, hypoxia, and topoisomerase inhibitor actions (Table 1, Additional file 1) were processed according to the above scheme of meta-analysis with a $p$ value cutoff threshold of 0.05 . We picked only those genes that were exclusively up or downregulated in all the studies compared to their corresponding controls. Gene expression levels were combined between studies on different platforms using RefSeq ID obtained from the microarray annotation file. To analyze the effect of paclitaxel (Table 1, Additional file 1), all corresponding samples were combined into one set as these data came from the same source using Affymetrix GeneChip Human Genome U133 Plus 2.0 software. Differentially expressed genes were identified without meta-analysis techniques using only the limma R/Bioconductor package [31]. We could not find a sufficient number of datasets for the effect of radiation and tyrosine kinase inhibitors' effect in public repositories, and therefore, differentially expressed genes were independently identified for each separate dataset using only the limma R/Bioconductor package [31].

\section{Cell cultures}

Human ovarian (SKOV3), breast (MCF7), colorectal (HT29), cervix (Hela) adenocarcinoma, lung carcinoma (A549), hepatocellular carcinoma (HepG2), and glioblastoma (U87MG) cell lines were grown in DMEM (Sigma) supplemented with a $1 \%$ penicillin/streptomycin mixture (Gibco), $2 \mathrm{mM}$ glutamine (Gibco), and 10\% fetal bovine serum (HyClone) in a humidified 5\% CO2 incubator at $37{ }^{\circ} \mathrm{C}$. The cells were checked for signs of mycoplasma contamination.

\section{LC-MS/MS}

The LC-MS/MS analysis of SKOV3 cell lysates was performed in three replicates using a TripleTOF 5600+ mass spectrometer with a NanoSpray III ion source (ABSciex) coupled to a NanoLC Ultra 2D+ nano-HPLC system (Eksigent). The HPLC system was configured in trap-elute mode. For sample loading buffer and buffer A, we used a mixture of $98.9 \%$ water, $1 \%$ methanol, and $0.1 \%$ formic acid $(v / v)$. Buffer B was $99.9 \%$ acetonitrile and $0.1 \%$ formic acid $(v / v)$. Samples were loaded on a Chrom XP C18 trap column $(3 \mu \mathrm{m}, 120 \AA$, $350 \mu \mathrm{m} \times$ $0.5 \mathrm{~mm}$; Eksigent) at a flow rate of $3 \mu \mathrm{l} / \mathrm{min}$ for $10 \mathrm{~min}$ and eluted through a 3C18-CL-120 separation column (3 $\mu \mathrm{m}, 120 \AA, 75 \mu \mathrm{m} \times 150 \mathrm{~mm}$; Eksigent) at a flow rate of $300 \mathrm{nl} / \mathrm{min}$. The gradient was increased from 5 to $40 \%$ buffer B over $90 \mathrm{~min}$ followed by $10 \mathrm{~min}$ at $95 \%$ buffer B and 20 min of reequilibration with $5 \%$ buffer B. Between different samples, two blank 45-min runs consisting of 5 to 8 min waves ( $5 \%$ B, 95\%, 95\%, 5\%) were required to wash the system and prevent carryover.

The information-dependent mass spectrometry experiments included one survey MS1 scan followed by 50 dependent MS2 scans. The following MS1 acquisition parameters were used: the mass range for MS2 analysis was $300-1250 \mathrm{~m} / \mathrm{z}$, and the signal accumulation time was $250 \mathrm{~ms}$. The ions used for the MS2 analysis were selected based on intensity with a threshold of $200 \mathrm{cps}$ and a charge state from 2 to 5. The following MS2 acquisition parameters were used: the resolution of the quadrupole was set to UNIT (0.7 Da), the measurement mass range was $200-1800 \mathrm{~m} / \mathrm{z}$, and the signal accumulation time was $50 \mathrm{~ms}$ for each parent ion. Collision-activated dissociation was performed using nitrogen gas and by ramping collision energy from 25 to $55 \mathrm{~V}$ within a signal accumulation time of $50 \mathrm{~ms}$. Analyzed parent ions were sent to a dynamic exclusion list for $15 \mathrm{~s}$ to obtain MS2 spectra at the chromatographic peak apex. A $\beta$-galactosidase tryptic solution (20 fmol) was run with a 15 -min gradient $(5-25 \%$ buffer B) between samples to calibrate the mass spectrometer and control overall system performance, stability and reproducibility.

Descriptions of further bioinformatics (pathway analysis, time clusterization analysis, co-regulation analysis, LC-MS/ MS protein identification) and experimental methods (SDS-PAGE, in-gel trypsin digestion, cell proliferation assay, flow cytometry, immunofluorescence analysis and western blotting) are provided in Additional file 2.

\section{Results}

The action of different chemotherapeutic drugs leads to intron retention in genes involved in splicing regulation

To determine how pre-mRNA splicing in cancer cells is affected by chemotherapy, we analyzed publicly available transcriptome datasets (GSE89127) that represent melanoma, lung cancer, gastric carcinoma, and bladder carcinoma cell lines (A375, A549, H3122, N87, PC9, RT112) treated with multiple kinase inhibitors (erlotinib, crizotinib, trametinib, lapatinib, vemurafenib, BGJ398) [34] (Table 1). In total, we detected 12,203 altered alternative splicing events in intact cells and cells exposed to 
kinase inhibitors. Interestingly, among them, 367 splicing events were observed in at least half of the cell lines after the therapy (Additional file 3A). Analysis of genes affected by alternative splicing revealed significant number of genes from the pre-mRNA splicing pathway (Fig. 1a). Thus, we assumed a regulatory feedback mechanism between the spliceosomal proteins and their targets. In other words, therapy-induced alterations in pre-mRNA splicing affect spliceosomal genes, which in turn may provoke further splicing perturbations. To assess possible effects of splicing changes on gene expression, we investigated types of alternative splicing events that occurred after therapy. Our analysis revealed two common splicing alterations: exon skipping (184 events) and intron retention (46 events) (Fig. 1b). In contrast to exon skipping, intron retention was observed more frequently after the therapy, i.e., in most cases the intron inclusion level was higher in treated samples than in untreated control cells (Fig. 1c). Analysis of transcripts with retained introns demonstrated that all of them contain multiple in frame stop codons (Additional file 3B). Therefore, they could not be translated into functional proteins $[35,36]$. Our data indicate that the spliceosome pathway might be suppressed by chemotherapy.

To further examine our hypothesis in a more clinically relevant model, we analyzed a publicly available transcriptome dataset (GSE69405) that represents 12 lung adenocarcinoma patient-derived xenograft (PDX) tumors prior to and after treatment with chemotherapeutic drugs, including carboplatin, docetaxel, afatinib, BEZ235, BKM120, DAPT, erlotinib, tivantinib, and selumetinib (Table 1). These data were used in the original study to compare gene expression levels without paying attention to mRNA splice variants [37]. Strikingly, we found that different drugs induced similar alterations in pre-mRNA splicing. This trend was further confirmed by PCA clustering of inclusion level differences between treated and untreated samples (Additional file 4: Figure S1). We detected 824 altered alternative splicing events in treated cells (Fig. 1b), and, similar to the previous dataset, the most frequent type of alternative splicing variants was intron retention. In total, more than half of samples had 47 common splicing events and 39 of them involved in intron retention (Fig. 1b, Additional file 3C, D).

As in the experiments conducted on cancer cell lines, in patient-derived tissues, a chemotherapy induces splicing alterations in genes involved in the spliceosome pathways (Fig. 1a). We observed intron retention in several essential splicing factors, including RBM6, HNRNPA2B1, RBM39, RBM5, SRRM1, SRSF5, and SRSF7 (Fig. 1d, Additional file 3E). Interestingly, treatment of cancer cells with different chemotherapeutic drugs resulted in retention of the same introns in each of these genes.
Chemotherapy and irradiation lead to a concerted change in the expression of spliceosomal and cell cycle genes

Having discovered that significant changes in pre-mRNA splicing in response to the action of various types of chemotherapeutic drugs, we next examined global changes in gene expression. We decided to perform analysis of mRNA levels in the same dataset that was used previously for evaluation of alternative splicing differences (GSE89127). It has revealed a significant downregulation of splicing-related gene levels in all cancer cell lines after chemotherapy (Fig. 1e). To expand this result to larger number of samples and multiple types of cancers, we performed six meta-analyses of mRNA microarray gene expression profiles of different cell lines exposed to various stress stimuli, including DNA-damaging agents (i.e., platinum-based drugs, gamma irradiation, and topoisomerase inhibitors), tyrosine kinase inhibitors, and taxanes (Fig. 2a). A detailed description of these datasets is presented in Table 1 and Additional file 1.

Our meta-analysis (Fig. 2b (top panel) and Additional file 5) revealed multiple downregulated and upregulated pathways, which were exclusively observed for certain drugs. For example, platinum-based compounds promoted the expression of genes responsible for apoptosis and those involved in the platinum drug resistance pathway (Additional file 5). While topoisomerase and tyrosine kinase inhibitors provoked the expression of apoptotic, lysosomal, and MAPK signaling genes. The only two pathways that were commonly affected in all tested datasets regardless of the treatment used were the cell cycle regulation (especially $\mathrm{M}$ phase regulation) and the pre-mRNA splicing pathways. The level of gene expression in these two pathways was significantly downregulated after treatment with anticancer drugs.

In clinical practice, platinum-based drugs are often combined with taxanes [38-40]. The cytostatic effect of taxanes is mainly associated with enhanced microtubule formation and stabilization [41]. The stimulation of microtubule formation temporarily activates CDK1 and triggers the $\mathrm{G} 2 / \mathrm{M}$ transition, which is followed by mitotic arrest [42]. It is in line with our meta-analysis of paclitaxel-treated cancer cells. The levels of genes involved in $M$ phase were significantly upregulated, while those associated with the $S$ phase and the G1/S transition were downregulated (Fig. 2b (bottom panel), Additional file 5). These data are consistent with previous findings $[41,43]$. Interestingly, we also observed a substantial increase in the transcription levels of genes involved in spliceosome assembly and regulation and in RNA transport.

Next, we studied the response of cancer cells to hypoxia, which is one of the natural stress factors for cancer cells. The result of corresponding dataset analysis was not so surprising: the spliceosomal and cell cycle 


\section{a}

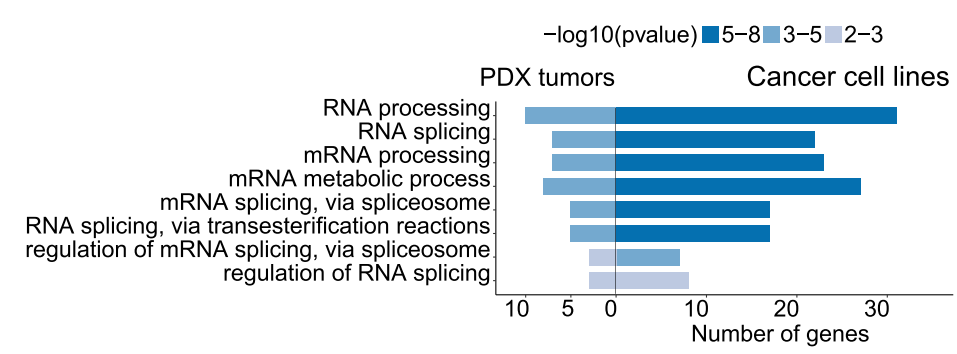

b

\begin{tabular}{|c|c|c|c|c|c|}
\hline 0 & \multirow[b]{2}{*}{ Alt. event } & \multicolumn{2}{|c|}{$\begin{array}{l}\text { Cancer cell lines, } \\
\text { target therapy }\end{array}$} & \multicolumn{2}{|c|}{$\begin{array}{l}\text { PDX tumors, } \\
\text { multiple drugs }\end{array}$} \\
\hline & & before & after & before & after \\
\hline SE & & $2242 / 57$ & $5272 / 184$ & $101 / 1$ & $186 / 4$ \\
\hline A3SS & 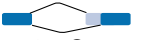 & $288 / 7$ & $725 / 11$ & $15 / 1$ & $39 / 3$ \\
\hline MXE & $\hat{-}$ & $441 / 10$ & $982 / 7$ & $58 / 0$ & $33 / 0$ \\
\hline RI & - & $406 / 26$ & $887 / 46$ & $31 / 0$ & $326 / 39$ \\
\hline A5SS & $2-1$ & $265 / 9$ & $695 / 10$ & $10 / 1$ & $25 / 1$ \\
\hline
\end{tabular}

\section{d}
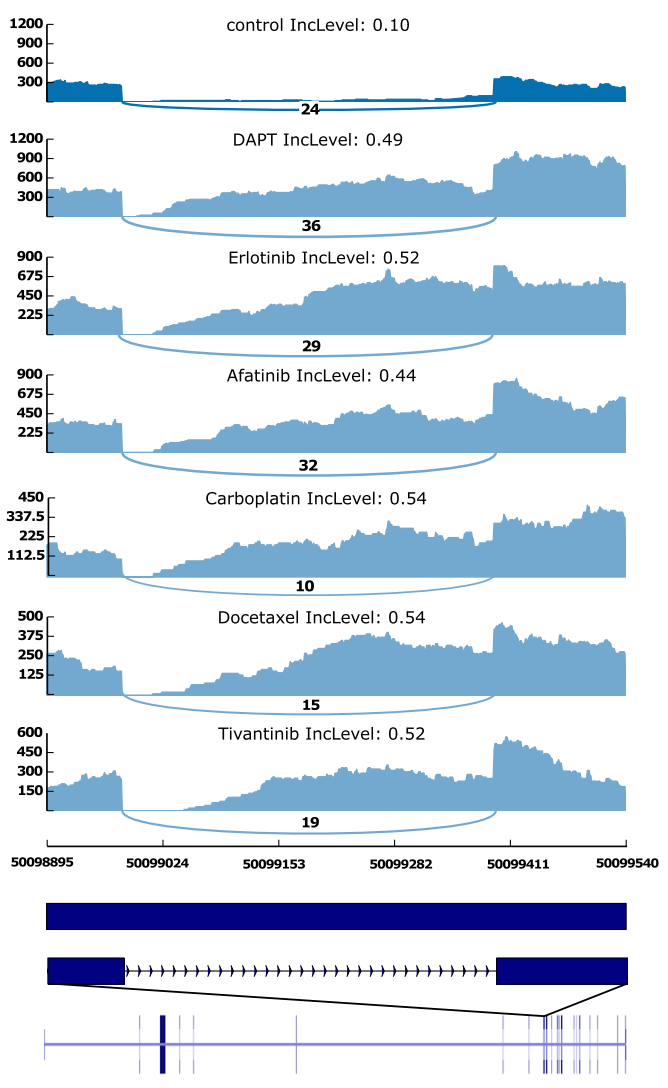

e

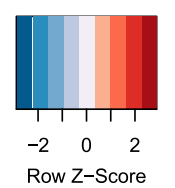

Row Z-Score
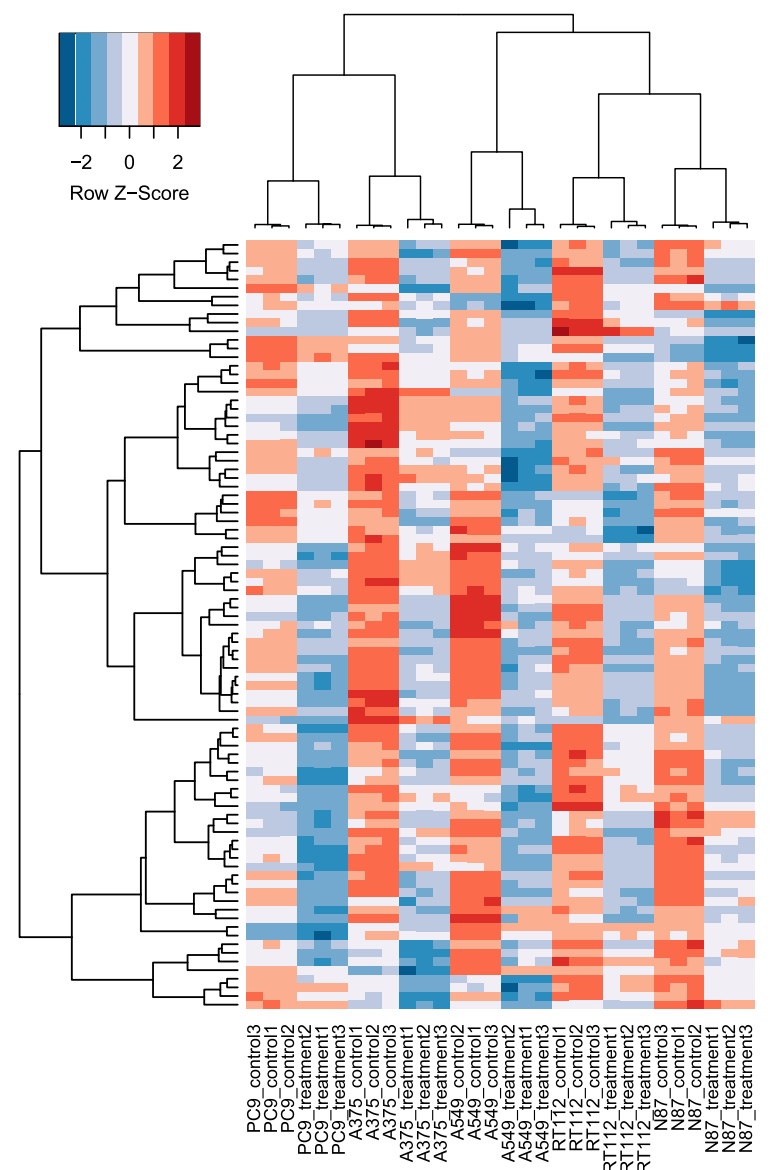

年

C other splicing-related genes
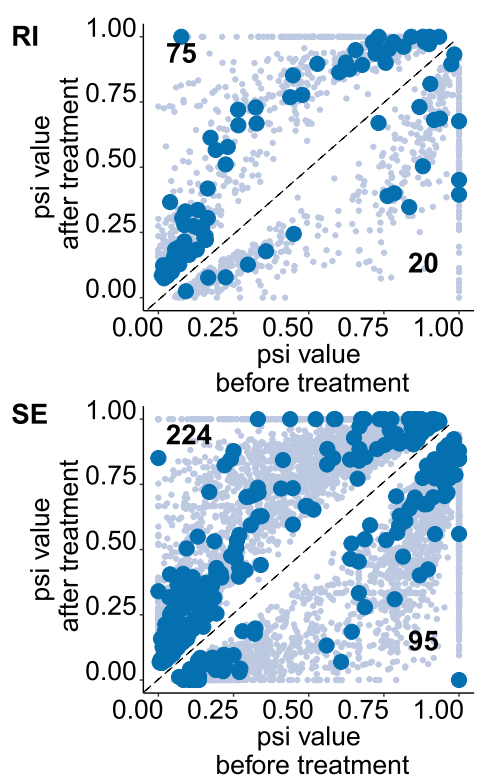


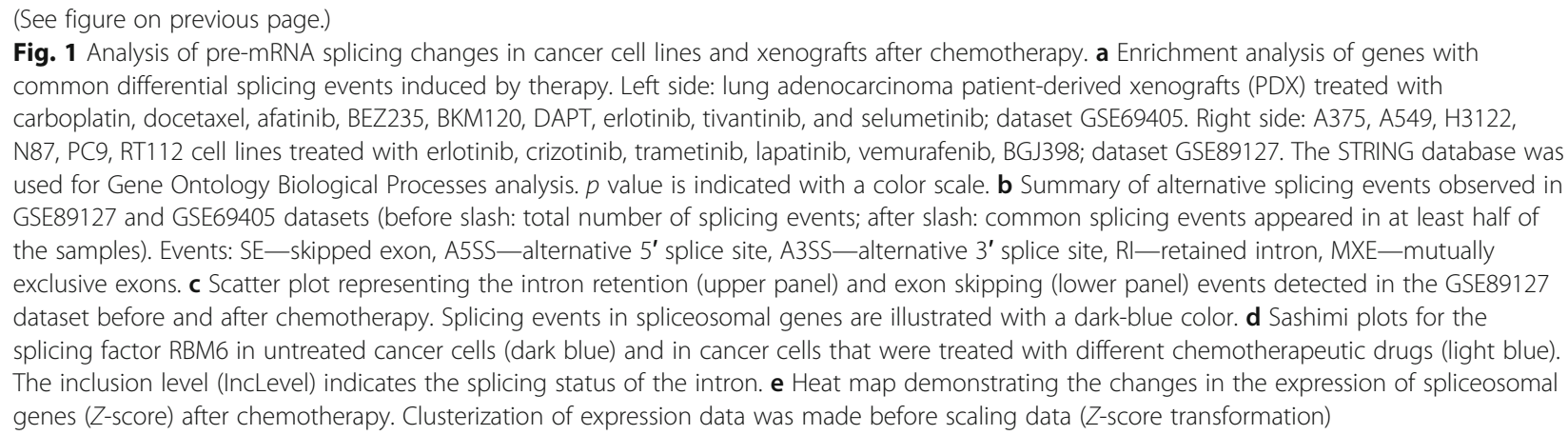

progression genes were found in the cluster of downregulated pathways (Fig. 2b (top panel), Additional file 5). In particular, the level of transcripts associated with $M$ phase of the cell cycle were significantly downregulated (Fig. 2b (bottom panel)).

Taken together, in our analysis of gene expression in 101 cell lines that were affected by six different types of stress, we identified only two pathways that were altered in all tested samples. The downregulation of cell cycle-related pathways was expected since it has recently been shown that stress induces retardation or arrest of specific cell cycle phases [43, 44]. Surprisingly, in addition to cell cycle changes, we consistently observed concerted changes in the expression of spliceosomal genes. To the best of our knowledge, this phenomenon has not been reported previously.

\section{Clusterization of time-series gene expression data revealed the same dynamics in the regulation of genes involved in cell cycle and splicing}

To understand the dynamics of changes in the expression of spliceosomal genes following exposure to different stress factors, we implemented soft clustering (i.e., fuzzy c-means clustering). We analyzed two datasets containing at least four time points after the beginning of the treatment: an ovarian cancer cell line treated with cisplatin (E-GEOD-8057) and a glioma cell line subjected to hypoxia (E-GEOD-18494). For both datasets, the cluster analysis clearly showed that spliceosomal gene levels were gradually downregulated (Fig. 3 a, b; Additional file 6). In spliceosomal gene clusters, we also found genes that were associated with the cell cycle and DNA replication pathways (Additional file 6). In particular, cell cycle genes involved in $M$ and $S$ phase transitions were significantly downregulated. The simultaneous decrease in the expression levels of cell cycleand spliceosome-related genes indicates that the downregulation of splicing is not a consequence of cell cycle arrest. It is more likely represents an independent mechanism of the cell response to stress.
Next, we were interested whether the concerted downregulation of spliceosomal and cell cycle genes is unique to cancer cells. Therefore, we conducted the soft clustering analysis of the transcriptome of gamma-irradiated normal skin fibroblasts (dataset E-GEOD-59861) (Fig. 3c, Additional file 6). Strikingly, results showed that spliceosomal genes were significantly downregulated in gamma-irradiated fibroblasts and the clusters enriched with spliceosomal genes also contained genes involved in DNA replication and $M$ and $S$ phase cell cycle transitions. Our results imply that observed concerted downregulation of expression levels of genes involved in splicing and cell cycle regulation is not specific for cancer cells.

\section{Co-regulation network clusterization revealed common transcription factors for genes involved in mitosis and splicing}

Since spliceosomal genes and genes involved in the $M$ phase of the cell cycle were changed in a concerted manner, we wondered whether these genes were regulated by the same transcription factors. To answer this question, we performed a co-expression analysis of genes differentially expressed in cancer cells exposed to chemotherapeutic drugs and created a co-regulatory network based on ChIP-seq from the ReMap database. We selected four datasets (E-GEOD-66493, GSE13525, GSE66493, and GSE47856) that describe the effects of platinum agents on gene expression in different cancer cell lines.

For each dataset, we independently identified differentially expressed splicing- and mitotic-related genes and chose pairs with Spearman correlation coefficients greater than 0.7 and FDR-corrected $p$ value $<0.05$. Next, we determined transcription factors that bind to the promoter regions of the co-expressed genes in chosen pairs (for more detail see Additional file 2). Our analysis revealed three transcription factors that were common for all datasets, namely, SOX2, GFI1B, and TARDBP (Fig. 3d, Additional file 4: Figure S2A, B). We assumed that these 
a

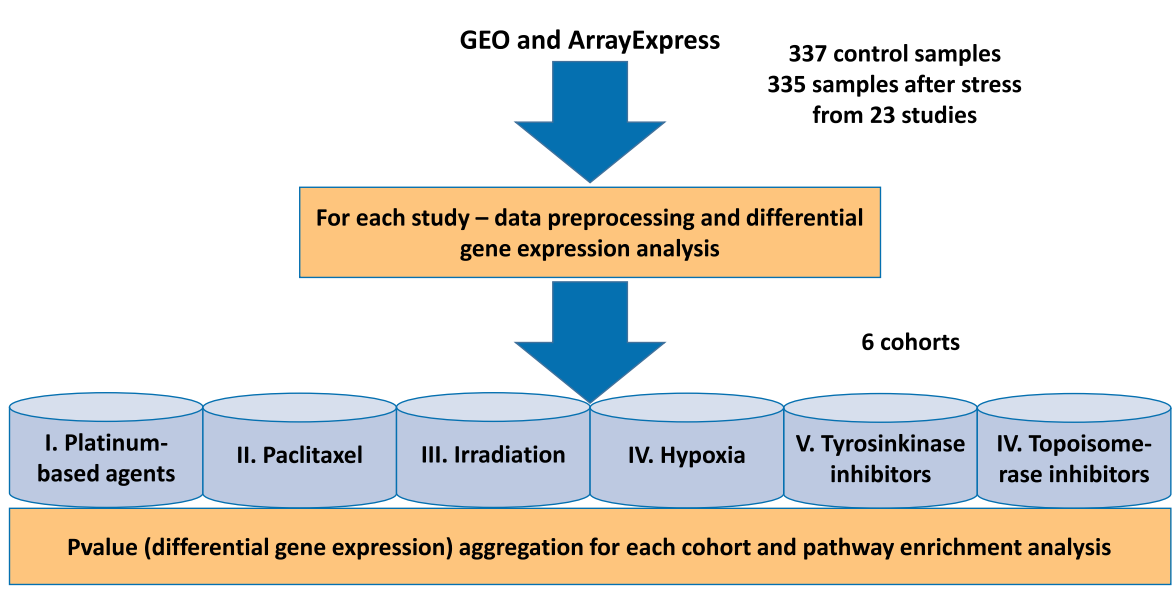

b

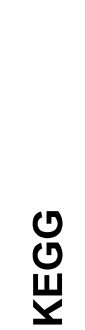

Mismatch repair

Homologous recombination Nucleotide excision repair Base excision repair Platinum drug resistance FoxO signaling pathway MAPK signaling pathway Endocytosis p53 signaling pathway Apoptosis Ribosome Proteasome Lysosome

M/G1 Transition

Cell Cycle, Mitotic $\stackrel{0}{\mathscr{c}}^{R}$

Regulation of mitotic cell cycle

M Phase G2/M Checkpoints Mitotic G2-G2/M phases $S$ Phase

Mitotic G1-G1/S phases Mitotic Spindle Checkpoint Cell Cycle Checkpoints

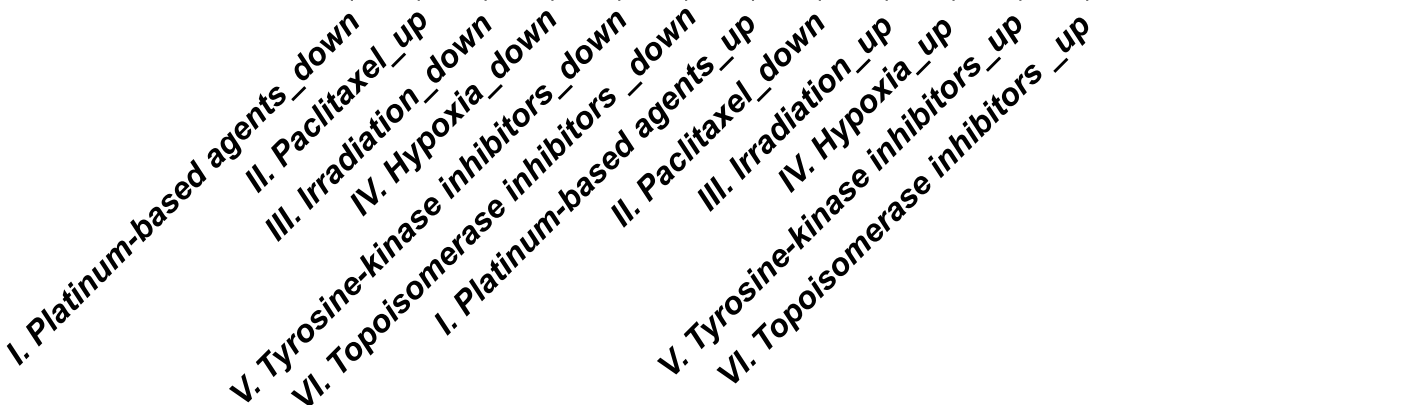

Fig. 2 Changes in gene expression in cancer cells in response to different stress conditions. a Workflow of the meta-analysis of mRNA microarray gene expression data. $\mathbf{b}$ Heat maps of selected pathways obtained by KEGG (top panel) and Reactome (bottom panel) enrichment analyses of up and downregulated genes in each of the six meta-analyses of gene expression 


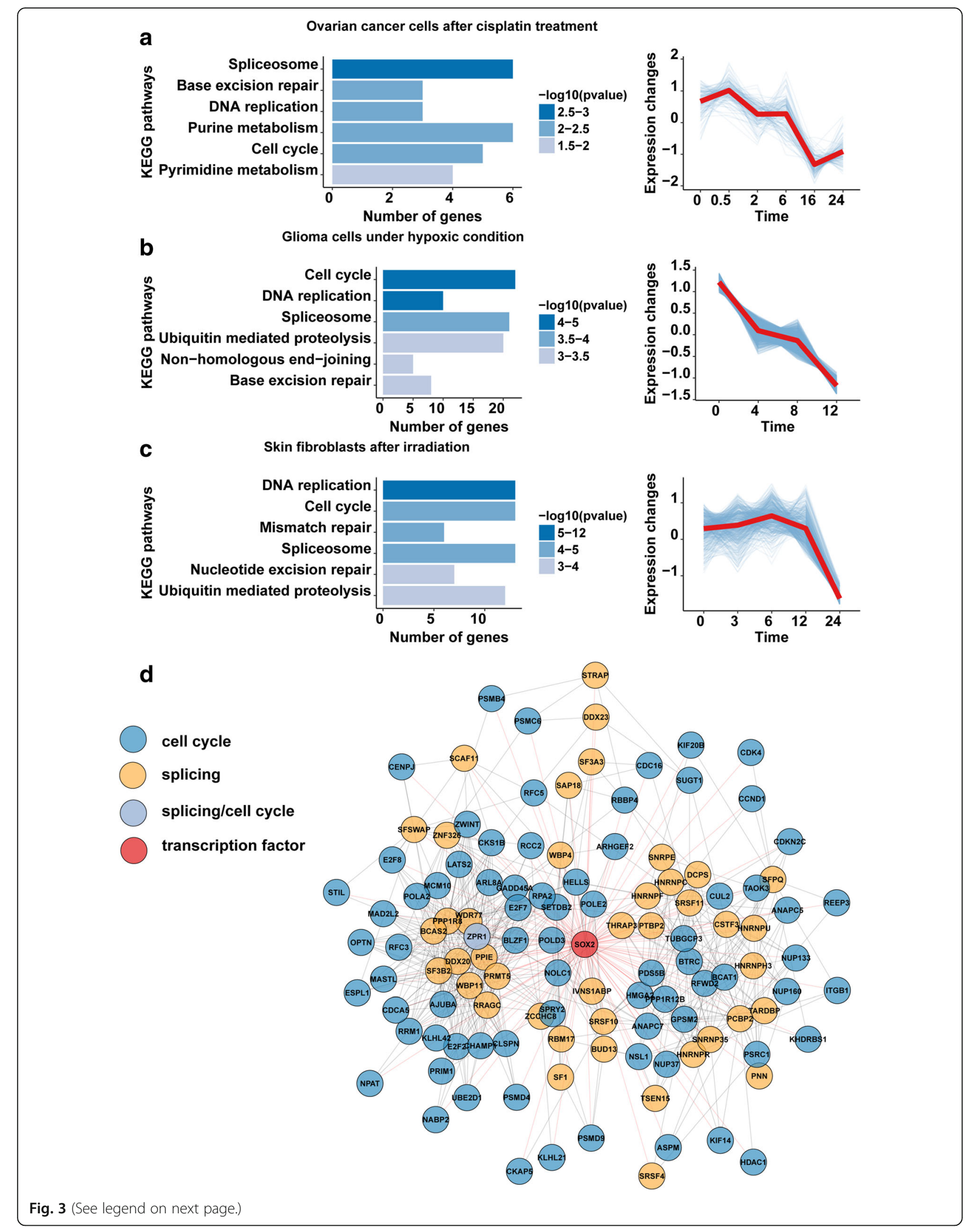


(See figure on previous page.)

Fig. 3 Different types of clusterization show concerted changes in the expression of spliceosomal and cell cycle genes. a-c Time clusterization of gene expression data (right panel) and subsequent pathway enrichment analysis (left panel) of clusters with highly represented spliceosomal genes. The clusters were constructed based on the following datasets: a E-GEOD-8057, b E-GEOD-18494, and c E-GEOD-59861. Blue lines represent $z$-score values of gene expression in each cluster. The red line is a mean value of $z$-score values of a cluster. $\mathbf{d}$ Graph representing the common transcription factor SOX2 that may induce concerted changes in the expression of pairs of mitotic and splicing genes after a course of chemotherapy. Solid black lines connect a pair of co-expressed genes, and red lines connect transcription factors with their target genes. Additional file 4: Figure S2A, B shows similar graphs for the transcription factors GFI1B and TARDBP

factors might be responsible for concerted gene expression changes in spicing- and mitotic-related genes.

\section{Chemotherapy induces phosphorylation and secretion of spliceosomal proteins}

In addition to the transcriptional control of gene expression, the activity of spliceosomal proteins can also be regulated at the proteome level by post-translational modifications. It has been shown that splicing can be inhibited by the phosphorylation of spliceosomal proteins as negatively charged phosphate groups obstruct binding between proteins and negatively charged RNA molecules [45-47]. Therefore, we analyzed three publicly available phosphoproteomes of cancer cells that were subjected to DNA damage (gamma irradiation or neocarzinostatin) [48-50] and compared proteins that were phosphorylated before and after treatment. According to our analysis, spliceosomal proteins were significantly phosphorylated after the therapy. In total, we identified 66 spliceosomal proteins with high post-treatment phosphorylation levels (Fig. 4a). These data favor the possibility that DNA damage may suppress the catalytic activity of spliceosomal proteins in cells.

In addition, several studies have shown that following exposure to chemo- [51] or radiotherapy [52] cancer cells specifically secrete spliceosomal proteins into the extracellular space. Consistent with these observations, we have previously identified multiple spliceosomal proteins in ovarian cancer ascites (extracellular fluids that serve as a natural medium for cancer cells) obtained from patients after treatment [51]. The proteins for which secretion increased more than twofold after radiotherapy of glioblastoma cells in vitro [52] and after chemotherapy of ovarian cancer cells both in vitro (cisplatin treatment) and in vivo (ascites from patients after combined course of chemotherapy) [51] are shown on Fig. 4b. In these datasets, we identified more than 30 spliceosomal proteins that could be exported from cancer cells in response to therapy. We validated these data by western blotting with antibodies against several spliceosomal proteins U2AF65, U2AF35, and RBM11 (Additional file 4: Figure S3).

To experimentally confirm the results of our meta-analyses, we performed LC-MS/MS-based proteome profiling of SKOV3 ovarian cancer cells before and
$24 \mathrm{~h}$ after treatment with cisplatin. In total, 3578 proteins were identified in our experiment (Fig. 4c, Additional file 7). Proteins were considered differentially present if their abundance was changed by more than twofold. We found that the abundance of 366 proteins were increased and the abundance of 922 proteins were decreased after cisplatin treatment. Data analysis using the KEGG database revealed that only three pathways were significantly altered in the treated cells (Fig. 4d). Interestingly, the spliceosome-related pathway proteins were substantially downregulated in accordance with our results of gene expression analyses.

\section{Small molecule splicing inhibitor impairs DNA damage response}

Based on the results on our transcriptomic and proteomic analyses, we conclude that alterations in pre-mRNA splicing are induced by multiple mechanisms during therapy: altered gene expression, pre-mRNA splicing dysregulation, protein post-translational modification and secretion. However, our analysis does not explain the biological reason for these changes. The role of the spliceosome in the DNA damage response has lately been demonstrated in several studies [53, 54]. Paulsen and colleagues performed full-genomic siRNA screening of human cells and identified that downregulation of genes involved in pre-mRNA splicing induced the highest level of H2AX phosphorylation [53], which serves as an early marker of the DNA damage response $[55,56]$. We collated the results of siRNA screening for histone H2AX phosphorylation [53] with the results of our meta-analysis of gene expression and proteomic data [51, 52] (Fig. 4e). Fisher's test showed that the proteins secreted by DNA-damaged cells are encoded by genes for which insufficient expression is perceived by the cell as a DNA repair signal (Fig. 4e). Therefore, the downregulation of several spliceosomal proteins that was observed during therapy may activate DNA reparation.

Based on these data, we proposed that the changes in alternative splicing and downregulation of spliceosomal transcripts and proteins that were observed after therapy may help cancer cells survive after genotoxic stress. To test this hypothesis, we treated ovarian (SKOV3), breast (MCF7), colorectal (HT29), cervix (Hela) adenocarcinoma, lung carcinoma (A549), hepatocellular carcinoma 


\section{a}

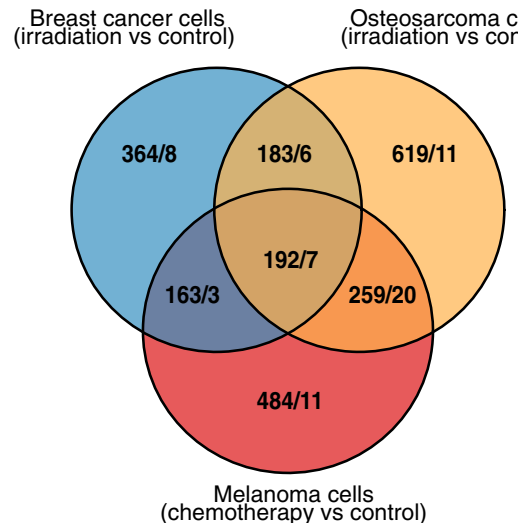

C

(chemotherapy vs control)

Proteome of ovarian cancer cells

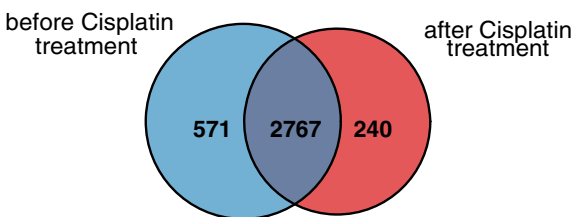

b
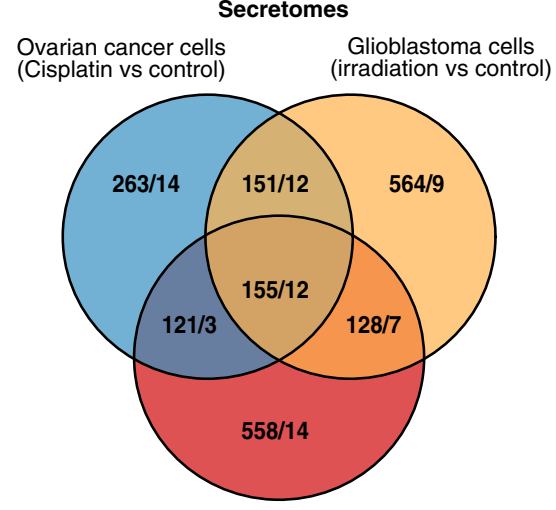

Ovarian cancer ascites (chemotherapy vs control)

d

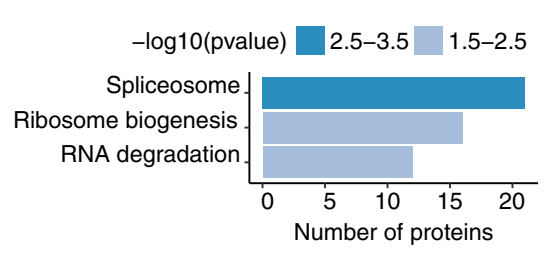

e

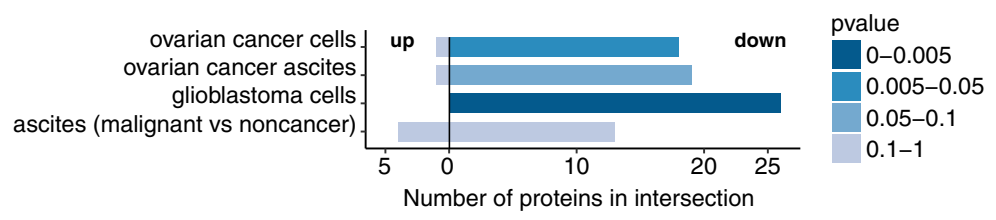

f

Splicing regulation after therapy

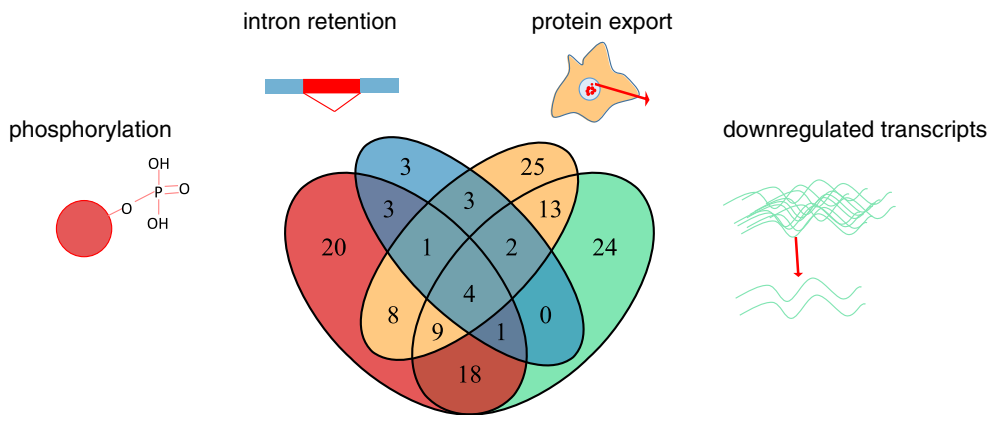

Fig. 4 Changes in proteomic profiles induced by different stress conditions. a Comparison of proteins that were phosphorylated in a breast cancer cell line after gamma-irradiation [49] (blue); in an osteosarcoma cancer cell line after gamma-irradiation [48] (orange) and in a melanoma cancer cell line after neocarzinostatin [50] (red). The number of spliceosomal proteins in a given sector is shown after the slash. b Venn diagram of upregulated proteins in therapy-induced secretomes of ovarian cancer cells (blue circle), glioblastoma cells (orange circle), and ovarian cancer ascites obtained from patients after the course of chemotherapy (red circle) [51,52]. The number of spliceosomal proteins in a given sector is shown after the slash. $\mathbf{c}$ Venn diagram representing the proteins identified in SKOV3 cells before (blue) and after (red) cisplatin treatment. $\mathbf{d}$ Results of the enrichment analysis of proteins (from " $\mathrm{C}$ ") for which abundance was decreased by more than twofold after chemotherapy. $\mathbf{e}$ Results of Fisher's test of the intersection between differentially secreted proteins (derived from data we reported in [51, 52]) and the hits from siRNA screening (based on the study by Paulsen et al. [53]). $\mathbf{f}$ Intersection of the lists of the spliceosomal genes with a decrease in expression (green circle, according to our meta-analyses of microarray data), intron retention in transcripts (blue circle, according to our meta-analyses of RNA-Seq data), upregulated secretion of the corresponding proteins (orange circle, according to our previous proteomic data) and upregulated protein phosphorylation (red circle, according to the analysis of phosphoproteomics data) observed after treatment with chemotherapeutic drugs 
(HepG2), and glioblastoma (U87MG) cell lines with sublethal doses of the small molecule splicing inhibitor pladienolide B for 2 days. After treatment, we evaluated the sensitivity of these cells to the DNA damaging drug cisplatin using an MTT assay (Fig. 5a, Additional file 4: Figure S4A). This experiment revealed that nanomolar concentrations of pladienolide $\mathrm{B}$ significantly increase the sensitivity of cancer cells to cisplatin (Fig. 5b, Additional file 4: Figure S4B).

To determine how splicing inhibitors affect cancer cells, we analyzed RNA sequencing data from ovarian adenocarcinoma cells (TOV21G; E-GEOD-67770) [57] treated with pladienolide $\mathrm{B}$ and cervix adenocarcinoma cells (Hela; GSE72156) [58] treated with another potent splicing inhibitor spliceostatin A with the same mechanism of action as pladienolide B. Figure 5e demonstrates that both inhibitors predominantly affect splicing of genes involved in the cellular stress response and cell cycle regulation. We confirmed these data through cell cycle analysis of HT29 and SKOV3 cells treated with pladienolide B (Additional file 4: Figure S4C).

Tressini and colleagues have recently demonstrated that spliceosomal complexes play an important role in the activation of ATM kinase and subsequent DNA repair [19]. This signaling pathway is activated by ATM autophosphorylation on Ser1981 [18]. Therefore, having obtained data indicating that pladienolide B impairs cell response to stress, we decided to investigate its effect on the level of phosphorylated ATM after DNA damage. FACS analysis and immunofluorescence microscopy demonstrated that pretreatment with pladienolide B dramatically decreases cisplatin-induced ATM phosphorylation in SKOV3, Hela, HT29, and A549 cells (Fig. 5c, d and Additional file 4: Figure S4D). Based on these data, we conclude that regulation of pre-mRNA splicing is important for ATM-dependent DNA damage response while dysregulation of spliceosomal machinery induced by a splicing inhibitor impairs ATM signaling and increases the sensitivity of cancer cells to genotoxic stress.

\section{Discussion}

Dysregulation of pre-mRNA splicing can lead to the appearance of protein isoforms that contribute to the initiation and progression of tumors and cancer resistance to chemotherapy $[5,59,60]$. In addition to the imbalance in splicing regulation that is inherent to cancer cells (as opposed to normal cells) [35, 61-63], the effectiveness and precision of pre-mRNA splicing are further affected by chemotherapy [4, 64]. Recent global analysis of splicing changes in tumor samples in comparison with normal tissues from TCGA collection revealed that aberrant alternative splicing often affected the functional domains of proteins, which frequently mutated in cancer [7]. The origin of cancer-related splicing changes remains mostly unknown. On the one hand, the global tendency of splicing dysregulation in cancer has been demonstrated in several excellent studies that revealed various cancer-associated mutations in spliceosomal genes that impair pre-mRNA splicing $[5,65,66]$. However, even in the absence of mutations in splicing factors, more intron retention events occur in cancer tissues than in normal cells [35]. On the other hand, many splicing factors are frequently overexpressed in multiple cancers [67]. Intriguingly, a growing number of studies demonstrates the functions of spliceosomal proteins that are not directly related to the splicing process such as DNA repair [68], R-loop formation [69], telomere elongation [20], mRNA export from the nucleus [70], and $\mathrm{M}$-phase regulation [71, 72].

Here, we comprehensively studied differences in alternative splicing and changes in the expression of spliceosomal genes in cancer cells following treatment with a variety of chemotherapeutic drugs. We analyzed publicly available poly(A)+ RNA-sequencing data and demonstrated that the most frequent alternative splicing event after chemotherapy was intron retention. Inefficient intron removal indicates less intense pre-mRNA splicing. It is important to note that poly $(\mathrm{A})+\mathrm{RNA}$-sequencing data could underestimate the extent of alternative splicing events because poly(A)+ RNA-seq depletes some fraction of intronic reads [73]; therefore, the real intron retention might be even higher then detected during our analysis. Our data strongly support the results of the meta-analyses, in which we observed a decrease in the expression of spliceosomal genes following exposure to several types of stress stimuli. To the best of our knowledge, this is the first study demonstrating an increase in the number of intron retention events in various cancer cells following different types of chemotherapy. Recently, one group of studies tried to recognize the regulation of one or a few transcripts following therapy [12-17]. Other studies focused only on exon inclusion/skipping events using splicing-sensitive microarrays. For example, it has been shown that camptothecin altered alternative splicing of genes involved in splicing regulation in MCF-7 and HCT116 cell lines [64, 74, 75]. Only a few works interrogated entire transcriptome changes after stress response. It has been reported that hypoxia and cisplatin treatment also affected the splicing of spliceosomal genes in breast cancer cell line [4, 76]. In our systematic analysis, we observed a similar enrichment pattern of alternative splicing changes across various cancer cell lines derived from different tumor types after exposure to various chemotherapeutic drugs. We showed that genes most affected by intron retention were genes that encodes spliceosomal proteins. Intron retention usually leads to RNA degradation and may therefore provide an additional mechanism by which 

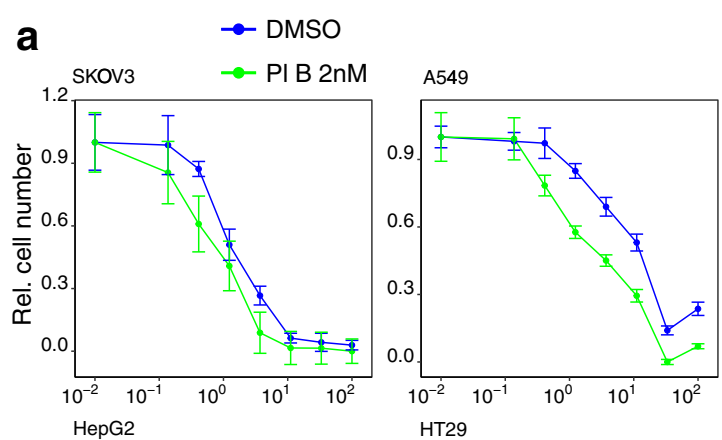

b
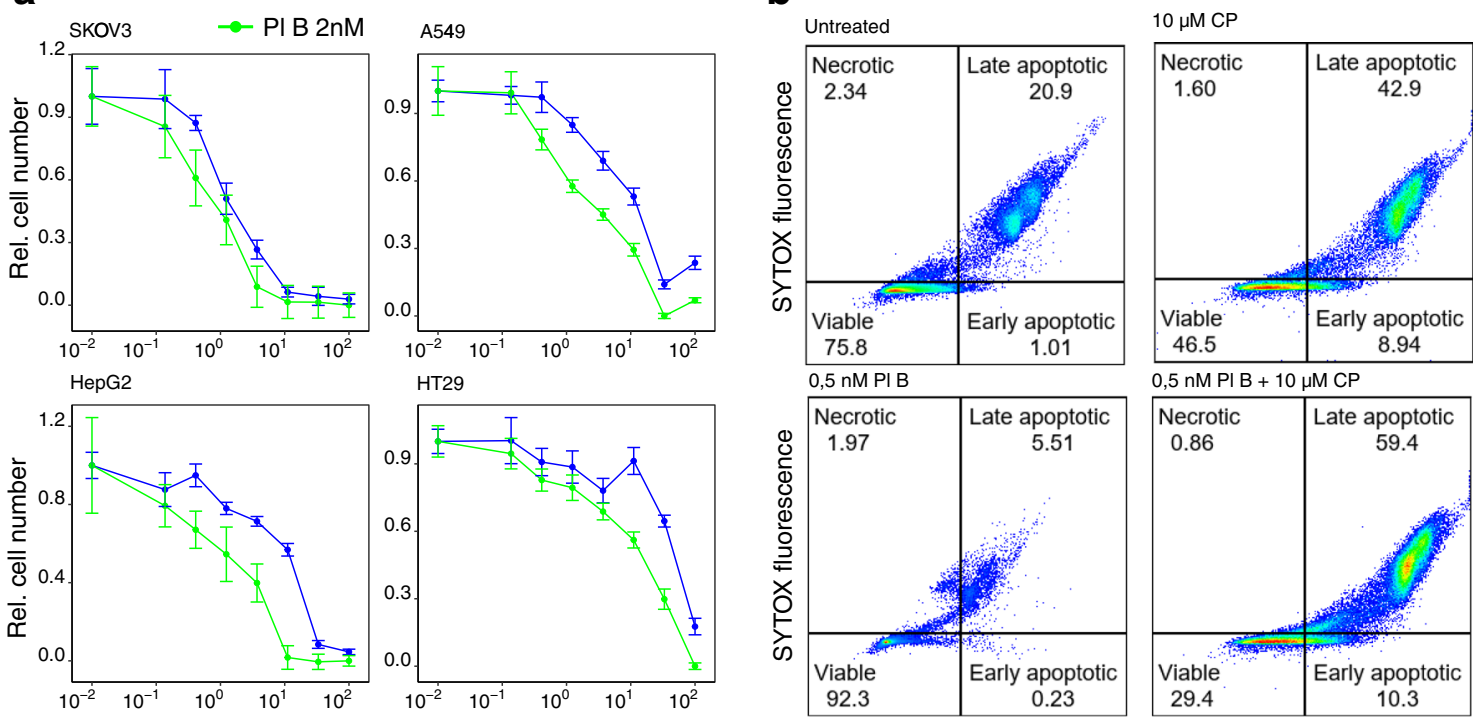

Cisplatin concentration $(\mu \mathrm{M})$

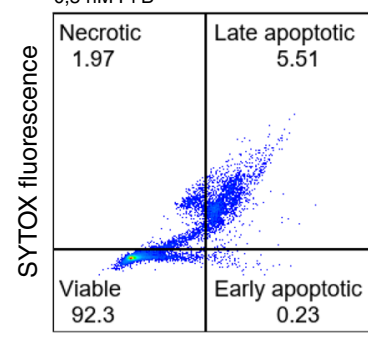

Caspase $3 / 7$ activity

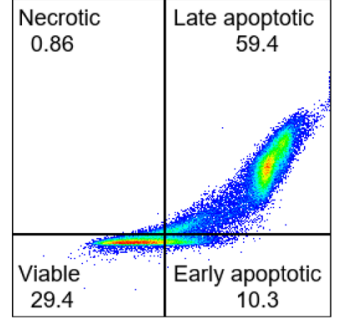

Caspase 3/7 activity

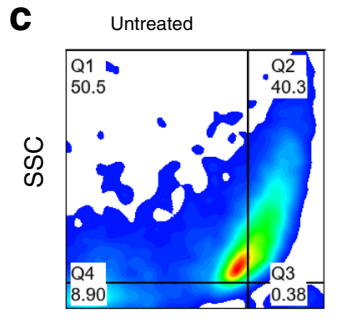

ATM (pS1981)

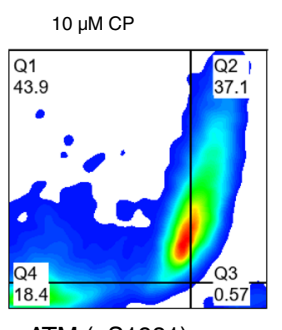

ATM (pS1981)

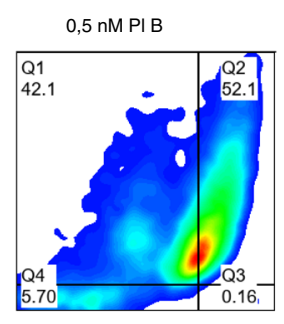

ATM (pS1981)

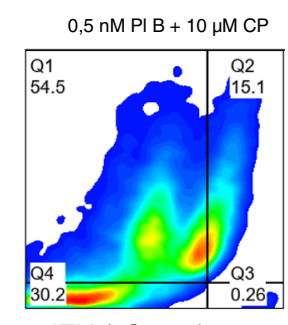

ATM (pS1981)

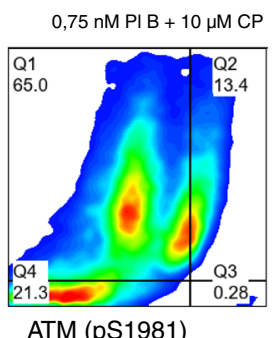

d

Untreated
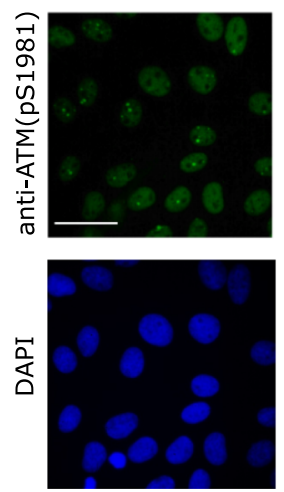

$10 \mu \mathrm{M} \mathrm{CP}$
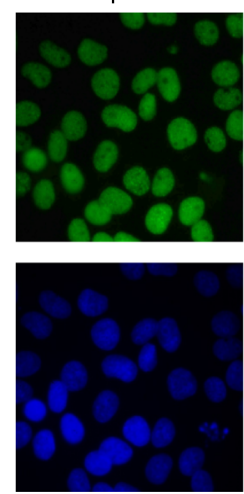
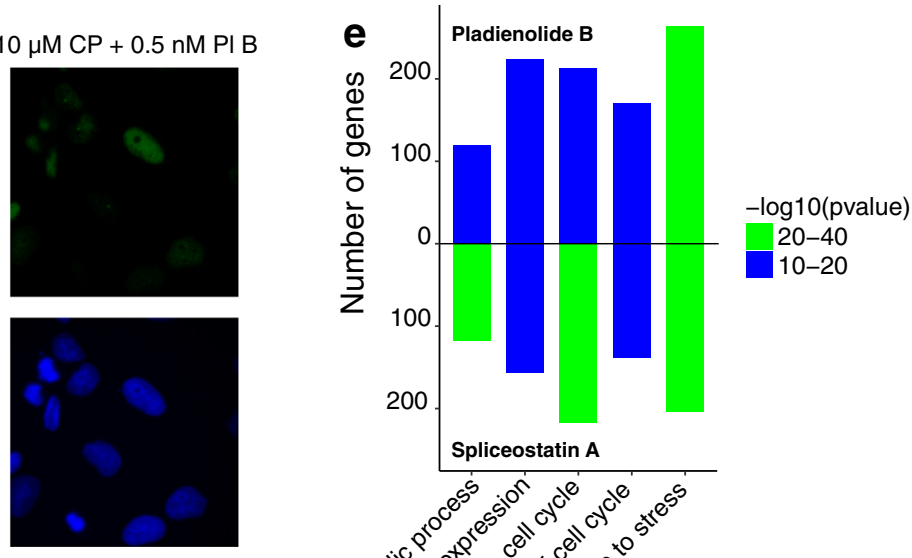

Fig. 5 (See legend on next page.) 
(See figure on previous page.)

Fig. 5 Pladienolide B impairs pre-mRNA splicing and increases the sensitivity of cancer cells to cisplatin. a Viability assay of SKOV3, A549, HepG2, and HT29 cells that were pretreated with $2 \mathrm{nM}$ pladienolide B (2 days) following treatment with different concentrations of cisplatin (4 days). $\mathbf{b}$ FACS analysis of caspase 3/7 and SYTOX staining of A549 cells treated with $0.5 \mathrm{nM}$ pladienolide B, $10 \mu \mathrm{M}$ Cisplatin or both drugs together. $\mathbf{c}$ FACS analysis of phospho ATM staining of SKOV3 cells that were cultivated with different concentrations of pladienolide B (2 days) and subsequently treated with $10 \mu \mathrm{M}$ Cisplatin (1 day). d Representative immunofluorescence images of SKOV3 cells stained for phosphoATM (S1981) (green) and with DAPI (blue) after treatment with $10 \mu \mathrm{M}$ Cisplatin in the presence or absence of $0.5 \mathrm{nM}$ Pladienolide B. Scale bar: $50 \mu \mathrm{m}$. e Enrichment analysis of genes affected by differential splicing events before and after treatment with splicing inhibitors: pladienolide B (upper part; E-GEOD-67770) and spliceostatin A (lower part; GSE72156). The STRING database was used for Gene Ontology Biological Processes analysis

downregulation of spliceosomal proteins is facilitated within the cell.

Intriguingly, the results of our meta-analyses of gene expression and the results of time clustering showed that spliceosomal genes and genes involved in the mitotic part of the cell cycle were simultaneously downregulated in different cell lines following exposure to various stresses. The only exception was the effect of taxanes. This group of drugs stimulates the G2/M transition and as a result upregulates genes involved in $\mathrm{M}$ phase. Importantly, we observed a simultaneous increase in spliceosomal genes after treatment with taxanes. Therefore, we observed concerted changes in the expression of spliceosomal and cell cycle-related genes following all types of treatment. An interplay between the cell cycle and the spliceosome has been demonstrated in many organisms, including yeast [77-82], fruit flies [83, 84], chickens [54], mice [85], and humans [54, 72, 86-90]. In human cells, inhibition of spliceosomal gene expression using siRNA led to multiple defects in cell cycle progression, most of which were related to mitosis [72, 86-88]. In addition, it has been shown that a lack of spliceosomal components causes cell cycle arrest in S and G2 phases [91, 92]. Furthermore, a connection between alternative splicing and cell cycle regulation has been demonstrated by Tsai and colleagues, who showed that alterations in pre-mRNA splicing are correlated with expression changes of genes involved in cell cycle regulation in cancer cells [93]. Therefore, there is a strong interplay between pre-mRNA splicing and proper cell cycle progression.

Our results show that the key transcription factors that regulate the concerted changes in the expression of spliceosomal and cell cycle genes were the proto-oncogenes SOX2 and GFI1B and the transcriptional repressor TARDBP. Changes in these transcription factors may play an oncogenic role in tumor formation [94-96]. SOX2 has been implicated in growth, tumorigenicity, drug resistance, and metastasis in at least 25 different cancers [97], TARDBP is involved in apoptosis and cell division, while GFI1B positively regulates c-Myc expression and increases the proliferation rate of cancer cells [98].

We showed that the amount of spliceosomal proteins in cells decreased after treatment with chemotherapeutic drugs through different molecular mechanisms. In addition to reduced expression and disturbances in splicing of spliceosomal genes, cancer cells secrete spliceosomal proteins into the extracellular space after a course of chemotherapy. Consistent with this observation, our LC-MS/MS-based proteomic profiling revealed a significant decrease in spliceosomal proteins inside cancer cells after chemotherapy. Interestingly, we also observed DNA damage-induced hyperphosphorylation of spliceosomal proteins. This post-translational modification is known to inhibit splicing catalysis [45-47]. Therefore, these data demonstrate that four independent mechanisms are activated in response to therapy-induced stress to decrease the number of spliceosomal proteins. These processes act at different levels (i.e., affecting gene expression, pre-mRNA splicing, protein post-translational modification and secretion) and are likely complementary to each other. In other words, they occur simultaneously in response to strong cellular stress and may affect more than two thirds of all spliceosomal proteins within the cell [99] (Fig. 4f).

However, it is important to note that downregulation of spliceosomal proteins does not always lead to decreased splicing efficiency. Alternative splicing is regulated by an intricate network of enhancing and inhibiting splicing factors. Therefore, downregulation of a splicing inhibitor protein may in fact lead to increased splicing efficiency. Moreover, multiple studies have demonstrated that depending on context the same protein may both repress and activate splicing, giving rise to complex regulatory relationships [5]. We believe that the therapy-induced downregulation of spliceosomal proteins may lead to highly specific alterations in pre-mRNA splicing and promote the survival of cancer cells after treatment. In our study, we utilized a small molecule splicing inhibitor that impairs the function of spliceosomal machinery. We speculate that it induces dysregulation of pre-mRNA splicing and therefore does not allow cells to fine tune their splicing in response to genotoxic stress. Failure to adjust splicing after DNA damage may in turn promote cell death. In agreement with this hypothesis, we demonstrated that pladienolide B significantly increases cisplatin-induced apoptosis and impedes DNA reparation. This synergetic effect of pladienolide $\mathrm{B}$ with cisplatin may allow the use of lower 
doses of both compounds in cancer treatment and therefore overcome side effects observed in patients during therapy [24].

Several previously published studies have shown that removal of spliceosomal proteins may activate DNA repair in cancer cells. Most recently, the U2/U5/U6 ribonucleoprotein complex of the spliceosome, which participates in the last stage of splicing, was found to dissociate from chromatin in response to UV radiation [19]. In addition, a lack of spliceosomal proteins inside the cell leads to a high level of histone H2AX phosphorylation, which serves as a signal for subsequent DNA repair [53]. However, the exact mechanism of interplay between spliceosomal proteins and DNA repair remains unknown. It is important to mention that a reduction in splicing efficiency does not indicate a total loss of functional transcripts. Cells contain many protein-coding genes that possess only few or even no introns. Multiple studies have shown that mainly intron-poor genes are activated upon exposure to different stresses [100]. Hence, genes with few introns can be efficiently spliced even in the presence of a small number of functional spliceosomes, whereas the expression of genes with a higher number of introns or with weak splicing sites might be downregulated [101].

\section{Conclusions}

Our analysis revealed a novel stress response mechanism that was observed in 101 cell lines under 12 different conditions. After treatment of cancer cells with various drugs, we detected a reduction in the level of active spliceosomal proteins induced by different pathways, such as intron retention, decreased gene expression, phosphorylation, and extracellular export. These processes act at multiple levels and are likely complementary to each other, i.e., they occur in parallel following stress insults and can collectively affect more than two thirds of all spliceosomal proteins within the cell. The downregulation of spliceosomal components through these processes may promote cancer cells survival following therapy. This stress response mechanism can be inhibited by pladienolide $B$, which significantly increases the sensitivity of cancer cells to cisplatin, and therefore, pladienolide $\mathrm{B}$ is a candidate drug to improve the efficiency of cancer therapy.

\section{Additional files}

Additional file 1: Full information regarding the mRNA microarray gene expression datasets used in this study. The dataset title is used in the text as a dataset identifier. (PDF $171 \mathrm{~kb}$ )

Additional file 2: Supplementary materials and methods. (PDF $151 \mathrm{~kb}$ )

Additional file 3: (A) Description of all alternative splicing events in cancer cell lines after therapy. (B) Identification of stop codons in transcripts with retained introns, which were detected in at least half of cancer cell lines before and after chemotherapy. (C) Description of all alternative splicing events in PDX tumors after different types of therapy. (D) Identification of stop codons in transcripts with retained introns, which were detected in PDX tumors before and after chemotherapy. (E) Description of alternative splicing events in spliceosomal genes in PDX tumors after different types of therapy. (F) Description of insertions which were detected in 7 cell lines (A375, A549, H3122, N87, PC9, RT112, H358) used in our analysis of alternative splicing changes. (XLSX $716 \mathrm{~kb}$ )

Additional file 4: Figure S1. PCA clustering of splicing inclusion level differences between treated and untreated PDX tumors. Figure S2: Graph representing the common transcription factors GFI1B (A) and TARDBP (B) that may induce concerted changes in the expression of pairs of splicingand mitotic-related genes after a course of chemotherapy. Solid black lines connect a pair of co-expressed genes and red lines connect transcription factors with their target genes. Figure S3: Western blotting analysis of U87MG cells and their concentrated secretomes before and after treatment with $30 \mu \mathrm{M}$ Cisplatin (CP). Figure S4: Pladienolide B increases the sensitivity of cancer cells to Cisplatin. (A) Viability assay of U87MG, Hela and MCF-7 cells that were pretreated with $2 \mathrm{nM}$ Pladienolide B (2 days) following treatment with different concentrations of Cisplatin (4 days). (B) FACS analysis of caspase 3/7 and SYTOX staining of SKOV3 cells treated with $0.5 \mathrm{nM}$ Pladienolide B, $10 \mu \mathrm{M}$ Cisplatin or both drugs together. (C) Cell cycle analysis of SKOV3 and HT29 cells treated for 3 days with $0.5 \mathrm{nM}$ and $1 \mathrm{nM}$ Pladienolide B, respectively. (D) FACS analysis of phospho ATM staining in Hela, A549 and HT29 cells that were cultivated with $1 \mathrm{nM}$ Pladienolide B (2 days) and subsequently treated with the indicated concentrations of Cisplatin (1 day). (PDF $855 \mathrm{~kb}$ )

Additional file 5: Results of the enrichment analysis of genes that were differentially expressed in response to different stress factors. (XLSX $171 \mathrm{~kb})$

Additional file 6: Description of gene clusters identified by the time clusterization analysis. (XLSX $415 \mathrm{~kb}$ )

Additional file 7: Proteins and their peptides identified by a proteome analysis of SKOV3 cells prior to and after Cisplatin treatment. (XLSX 8686 kb)

\section{Abbreviations}

A3SS: Alternative 3' splice site; A5SS: Alternative 5' splice site; LC-MS/ MS: Liquid chromatography tandem-mass spectrometry; MXE: Mutually exclusive exons; NCBI: National Center for Biotechnology Information; PCA: Principal component analysis; PDX: Patient-derived xenograft; RI: Retained intron; SE: Skipped exon; TF: Transcription factor

\section{Acknowledgements}

We thank Dr. Grigory Stepanov for providing helpful comments about the manuscript. We thank Dr. Dmitry B. Staroverov for assistance with FACS experiments. We thank Dr. Veronika Boychenko for critical reading and editing the manuscript.

\section{Funding}

This work was supported by the Russian Science Foundation project nos. 17-75-20205 (K.S.A; for the LC-MS/MS analysis) and 14-50-00131 (G.P.A.; for the in vitro experiments); the Russian Foundation for Basic Research projects nos. 18-34-00622 (K.S.A.), 16-04-01414 (V.O.S.), 17-00-00172 (M.A.L.), 16-0401209 (M.S.P.), and 17-29-06056 (M.S.P.), the Scholarship of the President of the Russian Federation SP-4811.2018.4 (V.O.S.), the Grant of the President of the Russian Federation MK-6894.2018.4 (G.P.A.), the Program of the Presidium of the Russian Academy of Sciences "Molecular and Cellular Biology" project no. 0101-2015-0027 (M.S.P.).

\section{Availability of data and materials}

All data generated or analyzed during this study are included in this published article and its supplementary information files. The datasets used in this study are listed in Table 1 and Additional file 1. The mass spectrometry proteomics data have been deposited to the ProteomeXchange Consortium via the PRIDE [102] partner repository with the dataset identifier PXD007615 and https:// doi.org/10.6019/PXD007615. 


\section{Authors' contributions}

KSA, VOS, GPA, MSP, MAL, MIS, and VMG designed the research. KSA and GPA analyzed the data. KSA, VOS, MSP, PVS, and IOB performed the research. KSA, VOS, GPA, and MSP wrote the paper. All authors read and approved the final manuscript.

\section{Ethics approval and consent to participate}

Not applicable.

\section{Consent for publication}

Not applicable.

\section{Competing interests}

The authors declare that they have no competing interests.

\section{Publisher's Note}

Springer Nature remains neutral with regard to jurisdictional claims in published maps and institutional affiliations.

\section{Author details}

${ }^{1}$ Laboratory of Proteomics, Shemyakin-Ovchinnikov Institute of Bioorganic Chemistry of the Russian Academy of Sciences, Moscow 117997, Russia. ${ }^{2}$ Laboratory of Cell Biology, Federal Research and Clinical Center of Physical-Chemical Medicine of Federal Medical Biological Agency, Moscow 119435, Russia. ${ }^{3}$ Systems Biology Lab, Moscow Institute of Physics and Technology (State University), MoscowRegion, 141701, Russia. ${ }^{4}$ Laboratory of Membrane Bioenergetics, Shemyakin-Ovchinnikov Institute of Bioorganic Chemistry of the Russian Academy of Sciences, Moscow 117997, Russia. ${ }^{5}$ Laboratory of Proteomic Analysis, Federal Research and Clinical Center of Physical-Chemical Medicine of Federal Medical Biological Agency, Moscow 119435, Russia.

Received: 3 March 2018 Accepted: 7 June 2018

Published online: 27 June 2018

\section{References}

1. Holohan C, Van Schaeybroeck S, Longley DB, Johnston PG. Cancer drug resistance: an evolving paradigm. Nat Rev Cancer. 2013;13:714-26.

2. Housman G, Byler S, Heerboth S, Lapinska K, Longacre M, Snyder N, et al. Drug resistance in cancer: an overview. Cancer. 2014;6:1769-92.

3. Zahreddine $H$, Borden KLB. Mechanisms and insights into drug resistance in cancer. Front Pharmacol. 2013:4:28.

4. Gabriel M, Delforge Y, Deward A, Habraken Y, Hennuy B, Piette J, et al. Role of the splicing factor SRSF4 in cisplatin-induced modifications of pre-mRNA splicing and apoptosis. BMC Cancer. 2015;15:227.

5. Dvinge $\mathrm{H}$, Kim $\mathrm{E}$, Abdel-Wahab $\mathrm{O}$, Bradley RK. RNA splicing factors as oncoproteins and tumour suppressors. Nat Rev Cancer. 2016;16:413-30.

6. Oltean S, Bates DO. Hallmarks of alternative splicing in cancer. Oncogene. 2014;33:5311-8

7. Ramalho RF, Carraro DM. Increasing evidence for the presence of alternative proteins in human tissues and cell lines. Applied Cancer Research. 2017;37:10.

8. Hsu TY-T, Simon LM, Neill NJ, Marcotte R, Sayad A, Bland CS, et al. The spliceosome is a therapeutic vulnerability in MYC-driven cancer. Nature. 2015;525:384-8

9. Marcotte R, Sayad A, Brown KR, Sanchez-Garcia F, Reimand J, Haider M, et al. Functional genomic landscape of human breast cancer drivers, vulnerabilities, and resistance. Cell. 2016;164:293-309.

10. Young JH, Peyton M, Seok Kim H, McMillan E, Minna JD, White MA, et al. Computational discovery of pathway-level genetic vulnerabilities in nonsmall-cell lung cancer. Bioinformatics. 2016;32:1373-9.

11. Venables JP, Klinck R, Koh C, Gervais-Bird J, Bramard A, Inkel L, et al. Cancerassociated regulation of alternative splicing. Nat Struct Mol Biol. 2009;16: 670-6.

12. Merdzhanova G, Edmond V, De Seranno S, Van den Broeck A, Corcos L, Brambilla C, et al. E2F1 controls alternative splicing pattern of genes involved in apoptosis through upregulation of the splicing factor SC35. Cell Death Differ. 2008;15:1815-23.

13. Schwerk C, Schulze-Osthoff K. Regulation of apoptosis by alternative premRNA splicing. Mol Cell. 2005;19:1-13.
14. Shkreta L, Froehlich U, Paquet ER, Toutant J, Elela SA, Chabot B. Anticance drugs affect the alternative splicing of $\mathrm{BCl}-\mathrm{x}$ and other human apoptotic genes. Mol Cancer Ther. 2008;7:1398-409.

15. Chandler DS, Singh RK, Caldwell LC, Bitler JL, Lozano G. Genotoxic stress induces coordinately regulated alternative splicing of the p53 modulators MDM2 and MDM4. Cancer Res. 2006;66:9502-8.

16. Eduati F, Doldàn-Martelli V, Klinger B, Cokelaer T, Sieber A, Kogera F, et al. Drug resistance mechanisms in colorectal cancer dissected with cell typespecific dynamic logic models. Cancer Res. 2017;77:3364-75.

17. Pagliarini $V$, Naro C, Sette C. Splicing regulation: a molecular device to enhance cancer cell adaptation. Biomed Res Int. 2015;2015:543067.

18. O'Connor MJ. Targeting the DNA damage response in cancer. Mol Cell. 2015:60:547-60.

19. Tresini M, Warmerdam DO, Kolovos P, Snijder L, Vrouwe MG, Demmers JAA et al. The core spliceosome as target and effector of non-canonical ATM signalling. Nature. 2015;523:53-8.

20. Naro C, Bielli P, Pagliarini V, Sette C. The interplay between DNA damage response and RNA processing: the unexpected role of splicing factors as gatekeepers of genome stability. Front Genet. 2015;6:142.

21. Lenzken SC, Loffreda A. Barabino SML. RNA splicing: a new player in the DNA damage response. Int J Cell Biol. 2013;2013:153634.

22. Larrayoz M, Blakemore SJ, Dobson RC, Blunt MD, Rose-Zerilli MJJ, Walewska $R$, et al. The SF3B1 inhibitor spliceostatin A (SSA) elicits apoptosis in chronic lymphocytic leukaemia cells through downregulation of Mcl-1. Leukemia. 2016:30:351-60

23. Mizui Y, Sakai T, Iwata M, Uenaka T. Pladienolides, new substances from culture of streptomyces platensis Mer-11107. The Journal of. jstage.jst.go.jp; 2004; Available from: https://www.jstage.jst.go.jp/article/antibiotics1968/57/ 3/57_3_188/_article/-char/ja/.

24. Eskens FALM, Ramos FJ, Burger H, O'Brien JP, Piera A, de Jonge MJA, et al. Phase I pharmacokinetic and pharmacodynamic study of the first-in-class spliceosome inhibitor E7107 in patients with advanced solid tumors. Clin Cancer Res. 2013;19:6296-304.

25. Salton M, Misteli T. Small molecule modulators of pre-mRNA splicing in cancer therapy. Trends Mol Med. 2016;22:28-37.

26. Barrett T, Wilhite SE, Ledoux P, Evangelista C, Kim IF, Tomashevsky M, et al. NCBI GEO: archive for functional genomics data sets-update. Nucleic Acids Res. 2013:41:D991-5.

27. Shen S, Park JW, Lu Z-X, Lin L, Henry MD, Wu YN, et al. rMATS: robust and flexible detection of differential alternative splicing from replicate RNA-Seq data. Proc Natl Acad Sci U S A. 2014;111:E5593-601.

28. Kolesnikov N, Hastings E, Keays M, Melnichuk O, Tang YA, Williams E, et al. ArrayExpress update-simplifying data submissions. Nucleic Acids Res. 2014 Available from: https:/academic.oup.com/nar/article/43/D1/D1113/2436935.

29. Gautier L, Cope L, Bolstad BM, Irizarry RA. affy_analysis of Affymetrix GeneChip data at the probe level. Bioinformatics. Oxford Univ Press; 2004; Available from: https://academic.oup.com/bioinformatics/article/20/3/307/ 185980

30. Du P, Kibbe WA, Lin SM. lumi: a pipeline for processing Illumina microarray. Bioinformatics. 2008;24:1547-8.

31. Smyth GK. limma: linear models for microarray data. In: Gentleman R, Carey VJ, Huber W, Irizarry RA, Dudoit S, editors. Bioinformatics and Computational Biology Solutions Using R and Bioconductor. New York: Springer; 2005. p. 397-420.

32. Won S, Morris N, Lu Q, Elston RC. Choosing an optimal method to combine P-values. Stat Med. 2009;28:1537-53.

33. Dewey M. metap: meta-analysis of significance values. $\mathrm{R}$ package version 07 2016

34. Rusan M, Li K, Li Y, Christensen CL, Abraham BJ, Kwiatkowski N, et al. Suppression of adaptive responses to targeted cancer therapy by transcriptional repression. Cancer Discov. 2018;8:59-73.

35. Dvinge $H$, Bradley RK. Widespread intron retention diversifies most cancer transcriptomes. Genome Med. 2015;7:45.

36. Braunschweig U, Barbosa-Morais NL, Pan Q, Nachman EN, Alipanahi B, Gonatopoulos-Pournatzis T, et al. Widespread intron retention in mammals functionally tunes transcriptomes. Genome Res. 2014;24:1774-86.

37. Kim K-T, Lee HW, Lee H-O, Kim SC, Seo YJ, Chung W, et al. Single-cell mRNA sequencing identifies subclonal heterogeneity in anti-cancer drug responses of lung adenocarcinoma cells. Genome Biol. 2015;16:127.

38. Ozols RF. Current status of chemotherapy for ovarian cancer. Semin Oncol. 1995:22:61-6. 
39. Matsuo K, Eno ML, Im DD, Rosenshein NB. Chemotherapy time interval and development of platinum and taxane resistance in ovarian, fallopian, and peritoneal carcinomas. Arch Gynecol Obstet. 2010;281:325-8.

40. Rigas JR. Taxane-platinum combinations in advanced non-small cell lung cancer: a review. Oncologist. 2004;9(Suppl 2):16-23.

41. Horwitz SB. Taxol (paclitaxel): mechanisms of action. Ann Oncol. 1994; 5(Suppl 6):S3-6.

42. Ibrado AM, Kim CN, Bhalla K. Temporal relationship of CDK1 activation and mitotic arrest to cytosolic accumulation of cytochrome $C$ and caspase-3 activity during Taxol-induced apoptosis of human AML HL-60 cells. Leukemia. 1998;12:1930-6.

43. Weaver BA. How Taxol/paclitaxel kills cancer cells. Mol Biol Cell. 2014;25:2677-81.

44. Olive PL, Banáth JP. Kinetics of H2AX phosphorylation after exposure to cisplatin. Cytometry B Clin Cytom. 2009;76:79-90.

45. Edmond V, Moysan E, Khochbin S, Matthias P, Brambilla C, Brambilla E, et al. Acetylation and phosphorylation of SRSF2 control cell fate decision in response to cisplatin. EMBO J. 2011:30:510-23.

46. Zhou Z, Fu X-D. Regulation of splicing by SR proteins and SR proteinspecific kinases. Chromosoma. 2013;122:191-207.

47. Zhong $X-Y$, Ding J-H, Adams JA, Ghosh G, Fu X-D. Regulation of SR protein phosphorylation and alternative splicing by modulating kinetic interactions of SRPK1 with molecular chaperones. Genes Dev. 2009;23: 482-95.

48. Beli P, Lukashchuk N, Wagner SA, Weinert BT, Olsen JV, Baskcomb L, et al. Proteomic investigations reveal a role for RNA processing factor THRAP3 in the DNA damage response. Mol Cell. 2012;46:212-25.

49. Kennedy JJ, Yan P, Zhao L, Ivey RG, Voytovich UJ, Moore HD, et al. Immobilized metal affinity chromatography coupled to multiple reaction monitoring enables reproducible quantification of phospho-signaling. Mol Cell Proteomics. 2016;15:726-39.

50. Bensimon A, Schmidt A, Ziv Y, Elkon R, Wang S-Y, Chen DJ, et al. ATMdependent and -independent dynamics of the nuclear phosphoproteome after DNA damage. Sci Signal 2010;3:rs3.

51. Shender VO, Pavlyukov MS, Ziganshin RH, Arapidi GP, Kovalchuk SI, Anikanov NA, et al. Proteome-metabolome profiling of ovarian cancer ascites reveals novel components involved in intercellular communication. Mol Cell Proteomics. ASBMB. 2014;13:3558-71.

52. Pavlyukov MS, Mohyeldin A, Shender VO, Minata M, Wang J, Chen D, et al Intercellular transfer of splicing factors via extracellular vesicles promotes glioblastoma growth and therapy resistance. FASEB J. 2016;30:590. 2-590.2

53. Paulsen RD, Soni DV, Wollman R, Hahn AT, Yee M-C, Guan A, et al. A genome-wide siRNA screen reveals diverse cellular processes and pathways that mediate genome stability. Mol Cell. 2009;35:228-39.

54. Li X, Manley JL. Inactivation of the SR protein splicing factor ASF/SF2 results in genomic instability. Cell. 2005;122:365-78.

55. Fernandez-Capetillo O, Lee A, Nussenzweig M, Nussenzweig A. H2AX: the histone guardian of the genome. DNA Repair. 2004;3:959-67.

56. Stucki $M$, Jackson SP. gammaH2AX and MDC1: anchoring the DNAdamage-response machinery to broken chromosomes. DNA Repair. 2006;5:534-43.

57. Wan $Y$, Zheng $X$, Chen $H$, Guo $Y$, Jiang $H$, He $X$, et al. Splicing function of mitotic regulators links $\mathrm{R}$-loop-mediated DNA damage to tumor cell killing J Cell Biol. 2015;209:235-46.

58. Yoshimoto R, Kaida D, Furuno M, Burroughs AM, Noma S, Suzuki H, et al Global analysis of pre-mRNA subcellular localization following splicing inhibition by spliceostatin A. RNA. 2017;23:47-57.

59. Shapiro IM, Cheng AW, Flytzanis NC, Balsamo M, Condeelis JS, Oktay MH, et al. An EMT-driven alternative splicing program occurs in human breast cancer and modulates cellular phenotype. PLoS Genet. 2011;7:e1002218. Public Library of Science

60. Yae T, Tsuchihashi K, Ishimoto T, Motohara T, Yoshikawa M, Yoshida GJ, et al. Alternative splicing of CD44 mRNA by ESRP1 enhances lung colonization of metastatic cancer cell. Nat Commun. 2012;3:883.

61. Zhang J, Manley JL. Misregulation of pre-mRNA alternative splicing in cancer. Cancer Discov. 2013;3:1228-37.

62. Dominguez D, Tsai Y-H, Weatheritt R, Wang Y, Blencowe BJ, Wang Z. An extensive program of periodic alternative splicing linked to cell cycle progression. Elife. 2016;5. Available from: https://doi.org/10.7554/eLife.10288

63. David CJ, Manley JL. Alternative pre-mRNA splicing regulation in cancer: pathways and programs unhinged. Genes Dev 2010;24:2343-64.
64. Solier S, Barb J, Zeeberg BR, Varma S, Ryan MC, Kohn KW, et al. Genomewide analysis of novel splice variants induced by topoisomerase I poisoning shows preferential occurrence in genes encoding splicing factors. Cancer Res. 2010;70:8055-65.

65. Neelamraju Y, Gonzalez-Perez A, Bhat-Nakshatri P, Nakshatri H, Janga SC. Mutational landscape of RNA-binding proteins in human cancers. RNA Biol. 2018;15:115-29.

66. Maciejewski JP, Padgett RA. Defects in spliceosomal machinery: a new pathway of leukaemogenesis. Br J Haematol. 2012;158:165-73.

67. Sebestyén $E$, Singh $B$, Miñana B, Pagès A, Mateo F, Pujana MA, et al. Large-scale analysis of genome and transcriptome alterations in multiple tumors unveils novel cancer-relevant splicing networks. Genome Res. 2016;26:732-44.

68. Shkreta L, Chabot B. The RNA Splicing Response to DNA Damage. Biomolecules. 2015;5:2935-77.

69. Chan YA, Hieter P, Stirling PC. Mechanisms of genome instability induced by RNA-processing defects. Trends Genet. 2014;30:245-53.

70. Delaleau M, Borden KLB. Multiple Export Mechanisms for mRNAs. Cell. 2015: 4:452-73

71. Hofmann JC, Husedzinovic A, Gruss OJ. The function of spliceosome components in open mitosis. Nucleus. 2010;1:447-59.

72. Sundaramoorthy S, Vázquez-Novelle MD, Lekomtsev S, Howell M, Petronczki M. Functional genomics identifies a requirement of pre-mRNA splicing factors for sister chromatid cohesion. EMBO J. 2014;33:2623-42.

73. Zhao S, Zhang Y, Gamini R, Zhang B, von Schack D. Evaluation of two main RNA-seq approaches for gene quantification in clinical RNA sequencing: polyA+ selection versus rRNA depletion. Sci Rep 2018:8:4781

74. Dutertre M, Sanchez G, De Cian M-C, Barbier J, Dardenne E, Gratadou L, et al. Cotranscriptional exon skipping in the genotoxic stress response. Nat Struct Mol Biol. 2010;17:1358-66.

75. Dutertre M, Chakrama FZ, Combe E, Desmet F-O, Mortada H, Polay Espinoza $M$, et al. A recently evolved class of alternative 3 '-terminal exons involved in cell cycle regulation by topoisomerase inhibitors. Nat Commun. 2014;5:3395.

76. Han J, Li J, Ho JC, Chia GS, Kato H, Jha S, et al. Hypoxia is a key driver of alternative splicing in human breast cancer cells. Sci Rep. 2017:7:4108.

77. Ben-Yehuda S, Russell CS, Dix I, Beggs JD, Kupiec M. Extensive genetic interactions between PRP8 and PRP17/CDC40, two yeast genes involved in pre-mRNA splicing and cell cycle progression. Genetics. 2000;154:61-71.

78. Ben-Yehuda S, Dix I, Russell CS, McGarvey M, Beggs JD, Kupiec M. Genetic and physical interactions between factors involved in both cell cycle progression and pre-mRNA splicing in Saccharomyces cerevisiae. Genetics. 2000;156:1503-17.

79. Russell CS, Ben-Yehuda S, Dix I, Kupiec M, Beggs JD. Functional analyses of interacting factors involved in both pre-mRNA splicing and cell cycle progression in Saccharomyces cerevisiae. RNA. 2000;6:1565-72.

80. Burns CG, Ohi R, Mehta S, OToole ET, Winey M, Clark TA, et al. Removal of a single alpha-tubulin gene intron suppresses cell cycle arrest phenotypes of splicing factor mutations in Saccharomyces cerevisiae. Mol Cell Biol. 2002;22:801-15.

81. Dahan O, Kupiec M. Mutations in genes of Saccharomyces cerevisiae encoding pre-mRNA splicing factors cause cell cycle arrest through activation of the spindle checkpoint. Nucleic Acids Res. 2002;30:4361-70.

82. Kaplan Y, Kupiec M. A role for the yeast cell cycle/splicing factor Cdc40 in the G1/S transition. Curr Genet. 2007;51:123-40.

83. Somma MP, Ceprani F, Bucciarelli E, Naim V, De Arcangelis V, Piergentili R, et al. Identification of Drosophila mitotic genes by combining co-expression analysis and RNA interference. PLoS Genet. 2008;4:e1000126.

84. Andersen DS, Tapon N. Drosophila MFAP1 is required for pre-mRNA processing and G2/M progression. J Biol Chem. 2008;283:31256-67.

85. Kleinridders A, Pogoda H-M, Irlenbusch S, Smyth N, Koncz C, Hammerschmidt M, et al. PLRG1 is an essential regulator of cell proliferation and apoptosis during vertebrate development and tissue homeostasis. Mol Cell Biol. 2009:29:3173-85.

86. Kittler R, Putz G, Pelletier L, Poser I, Heninger A-K, Drechsel D, et al. An endoribonuclease-prepared siRNA screen in human cells identifies genes essential for cell division. Nature. 2004;432:1036-40.

87. van der Lelij P, Stocsits RR, Ladurner R, Petzold G, Kreidl E, Koch B, et al. SNW1 enables sister chromatid cohesion by mediating the splicing of sororin and APC2 pre-mRNAs. EMBO J. 2014;33:2643-58.

88. Huen MSY, Sy SMH, Leung KM, Ching Y-P, Tipoe GL, Man C, et al. SON is a spliceosome-associated factor required for mitotic progression. Cell Cycle. 2010:9:2679-85. 
89. Li Z, Pützer BM. Spliceosomal protein E regulates neoplastic cell growth by modulating expression of cyclin E/CDK2 and G2/M checkpoint proteins. J Cell Mol Med. 2008;12:2427-38.

90. Karamysheva Z, Díaz-Martínez LA, Warrington R, Yu H. Graded requirement for the spliceosome in cell cycle progression. Cell Cycle. 2015;14:1873-83.

91. Nelson SJ. Models for DNA damage formation and repair in mammalian cells exposed to ionizing radiation. Radiat Res. 1982;92:120.

92. Rocca CJ, Soares DG, Bouzid H, Henriques JAP, Larsen AK, Escargueil AE. BRCA2 is needed for both repair and cell cycle arrest in mammalian cells exposed to S23906, an anticancer monofunctional DNA binder. Cell Cycle. 2015;14:2080-90.

93. Tsai YS, Dominguez D, Gomez SM, Wang Z. Transcriptome-wide identification and study of cancer-specific splicing events across multiple tumors. Oncotarget. 2015;6:6825-39.

94. Postel-Vinay S, Véron AS, Tirode F, Pierron G, Reynaud S, Kovar H, et al. Common variants near TARDBP and EGR2 are associated with susceptibility to Ewing sarcoma. Nat Genet. 2012;44:323-7.

95. Boumahdi S, Driessens G, Lapouge G, Rorive S, Nassar D, Le Mercier M, et al. SOX2 controls tumour initiation and cancer stem-cell functions in squamous-cell carcinoma. Nature. 2014;511:246-50.

96. Anguita E, Candel FJ, Chaparro A, Roldán-Etcheverry JJ. Transcription factor GFI1B in health and disease. Front Oncol. 2017;7:54.

97. Wuebben EL, Rizzino A. The dark side of SOX2: cancer-a comprehensive overview. Oncotarget. 2017;8:44917-43.

98. Elmaagacli AH, Koldehoff M, Zakrzewski JL, Steckel NK, Ottinger $\mathrm{H}$, Beelen DW. Growth factor-independent 1B gene (GFI1B) is overexpressed in erythropoietic and megakaryocytic malignancies and increases their proliferation rate. Br J Haematol. 2007;136:212-9.

99. Zhou Z, Licklider LJ, Gygi SP, Reed R. Comprehensive proteomic analysis of the human spliceosome. Nature. 2002;419:182-5.

100. Jeffares DC, Penkett CJ, Bähler J. Rapidly regulated genes are intron poor. Trends Genet. 2008:24:375-8.

101. Singh J, Padgett RA. Rates of in situ transcription and splicing in large human genes. Nat Struct Mol Biol. 2009;16:1128-33.

102. Vizcaíno JA, Csordas A, Del-Toro N, Dianes JA, Griss J, Lavidas I, et al. 2016 update of the PRIDE database and its related tools. Nucleic Acids Res. 2016; 44:11033.

103. Rieswijk L, Lizarraga D, Brauers KJJ, Kleinjans JCS, van Delft JHM. Characterisation of cisplatin-induced transcriptomics responses in primary mouse hepatocytes, HepG2 cells and mouse embryonic stem cells shows conservation of regulating transcription factor networks. Mutagenesis. 2014; 29:17-26.

104. Bowden NA, Ashton KA, Vilain RE, Avery-Kiejda KA, Davey RJ, Murray HC, et al. Regulators of global genome repair do not respond to DNA damaging therapy but correlate with survival in melanoma. PLoS One. 2013;8:e70424.

105. Konstantinopoulos PA, Fountzilas E, Pillay K, Zerbini LF, Libermann TA, Cannistra SA, et al. Carboplatin-induced gene expression changes in vitro are prognostic of survival in epithelial ovarian cancer. BMC Med Genomics. 2008;1:59.

106. Brun YF, Varma R, Hector SM, Pendyala L, Tummala R, Greco WR. Simultaneous modeling of concentration-effect and time-course patterns in gene expression data from microarrays. Cancer Genomics Proteomics. 2008;5:43-53.

107. Van den Hof WFPM, Coonen MLJ, van Herwijnen M, Brauers K, Wodzig WKWH, van Delft JHM, et al. Classification of hepatotoxicants using HepG2 cells: a proof of principle study. Chem Res Toxicol. 2014;27:433-42.

108. Alborzinia H, Can S, Holenya P, Scholl C, Lederer E, Kitanovic I, et al. Realtime monitoring of cisplatin-induced cell death. PLoS One. 2011;6:e19714.

109. McEvoy LM, O'Toole SA, Spillane CD, Martin CM, Gallagher MF, Stordal B, et al. Identifying novel hypoxia-associated markers of chemoresistance in ovarian cancer. BMC Cancer. 2015;15:547.

110. Dezso Z, Oestreicher J, Weaver A, Santiago S, Agoulnik S, Chow J, et al. Gene expression profiling reveals epithelial mesenchymal transition (EMT) genes can selectively differentiate eribulin sensitive breast cancer cells. PLoS One. 2014;9:e106131.

111. Horton JK, Siamakpour-Reihani S, Lee C-T, Zhou Y, Chen W, Geradts J, et al. FAS death receptor: a breast cancer subtype-specific radiation response biomarker and potential therapeutic target. Radiat Res. 2015;184:456-69.

112. Hou J, Wang F, Kong P, Yu PKN, Wang H, Han W. Gene profiling characteristics of radioadaptive response in AG01522 normal human fibroblasts. PLoS One. 2015:10:e0123316.
113. Xia X, Kung AL. Preferential binding of HIF-1 to transcriptionally active loci determines cell-type specific response to hypoxia. Genome Biol. 2009;10:R113.

114. Olbryt M, Habryka A, Student S, Jarzab M, Tyszkiewicz T, Lisowska KM. Global gene expression profiling in three tumor cell lines subjected to experimental cycling and chronic hypoxia. PLoS One. 2014;9:e105104.

115. Lu X, Yan CH, Yuan M, Wei Y, Hu G, Kang Y. In vivo dynamics and distinct functions of hypoxia in primary tumor growth and organotropic metastasis of breast cancer. Cancer Res. 2010;70:3905-14.

116. Ji R-R, de Silva $H$, Jin $Y$, Bruccoleri RE, Cao J, He A, et al. Transcriptional profiling of the dose response: a more powerful approach for characterizing drug activities. PLoS Comput Biol. 2009:5:e1000512.

117. Dalmases A, González I, Menendez S, Arpí O, Corominas JM, Servitja S, et al. Deficiency in p53 is required for doxorubicin induced transcriptional activation of NF-?B target genes in human breast cancer. Oncotarget. 2014; 5:196-210.

118. Stockwin LH, Yu SX, Stotler H, Hollingshead MG, Newton DL. ARC (NSC 188491) has identical activity to Sangivamycin (NSC 65346) including inhibition of both P-TEFb and PKC. BMC Cancer. 2009;9:63.

119. Iorio F, Bosotti R, Scacheri E, Belcastro V, Mithbaokar P, Ferriero R, et al. Discovery of drug mode of action and drug repositioning from transcriptional responses. Proc Natl Acad Sci U S A. 2010;107:14621-6.

120. Bailey ST, Shin H, Westerling T, Liu XS, Brown M. Estrogen receptor prevents p53-dependent apoptosis in breast cancer. Proc Natl Acad Sci U S A. 2012; 109:18060-5.

\section{Ready to submit your research? Choose BMC and benefit from:}

- fast, convenient online submission

- thorough peer review by experienced researchers in your field

- rapid publication on acceptance

- support for research data, including large and complex data types

- gold Open Access which fosters wider collaboration and increased citations

- maximum visibility for your research: over $100 \mathrm{M}$ website views per year

At BMC, research is always in progress.

Learn more biomedcentral.com/submissions 